\title{
A Praça de Casa Forte: um jardim histórico, um patrimônio cultural do Brasil
}

The Casa Forte Square: a historic garden, a cultural heritage of Brazil

http://dx.doi.org/10.1590/1982-02672019v27e05

JOELMIR MARQUES DA SILVA'

Universidade Federal de Pernambuco / Recife, PE, Brasil

https:/ / orcid.org/0000-0002-8323-7171

ANA RITA SÁ CARNEIRO²

Universidade Federal de Pernambuco / Recife, PE, Brasil

https://orcid.org/0000-0002-2750-5354

WILSON DE BARROS FEITOSA JÚNIOR³

Universidade Federal de Pernambuco / Recife, PE, Brasil

https:/ / orcid.org/0000-000 1-9992-3566

\section{MARIA EDUARDA DANTAS DE OLIVEIRA ROLIM ${ }^{4}$}

Universidade Federal de Pernambuco / Recife, PE, Brasil

https://orcid.org/0000-0002-2143-5463

RESUMO: $O$ jardim moderno brasileiro foi criado em Recife por Roberto Burle Marx na década de 1930. Ele concebia o jardim como uma reintegração estética dos elementos da natureza onde a vegetação era elemento principal. Com essa intenção, projetou treze jardins públicos entre 1935 e 1937, incluindo a Praça de Casa Forte, seu primeiro projeto. Sendo o jardim perecível e renovável, segundo a Carta de Florença, por toda dinâmica física e biológica, a falta de conservação provoca sua degradação. Assim sendo, apresenta-se neste artigo a historiografia da Praça de Casa Forte, de forma a subsidiar ações efetivas de conservação.

\begin{abstract}
1. Professor do Departamento de Arquitetura e Urbanismo, pesquisador do Laboratório da Paisagem e da Inciti: Pesquisa e Inovação para as Cidades, todos da Universidade Federal de Pernambuco (UFPE). Membro do Comitê Internacional de Paisagens Culturais(Icomos/Ifla). Biólogo. Mestre e doutor em Desenvolvimento Urbano pela UFPE. Mestre em Diseño, Planificación y Conservación de Paisajes y Jardines pela Universidad Autónoma Metropolitana, México. E-mail: <joelmir_ marques@hotmail.com>
\end{abstract}

\footnotetext{
2. Professora do Departamento de Arquitetura e Urbanismo e coordenadora do Laboratório da Paisagem, ambos da UFPE. Membro do Comitê Internacional de Paisagens Culturais (Icomos/Ifla), da Associação Brasileira de Arquitetos Paisagistas (Abap) e do Icomos/Brasil. Arquiteta pela UFPE, mestre em Desenvolvimento Urbano pela mesma instituição e doutora em Arquitetura pela Oxford Brookes University.
} 
E-mail: <anaritacarneiro@ hotmail.com>

3. Arquiteto e urbanista. Pesquisador do Laboratório da Paisagem do Departamento de Arquitetura e Urbanismo da UFPE. Bolsista da Fundação de Amparo à Ciência e Tecnologia do Estado de Pernambuco (Bolsa de Fixação de Técnico - BFT). E-mail: <wilsonbarrosf@ gmail.com>

4. Graduanda em Arquitetura e Urbanismo da UFPE. E-mail: <eduarda. dantas0194@gmail.com>
PALAVRAS-CHAVE: Arte. Conservação do patrimônio cultural. Jardim moderno.

ABSTRACT: Roberto Burle Marx created the Brazilian modern garden in Recife in the 1930s. He conceived the garden as an esthetic reintegration of the components of nature in which vegetation was the main element and, considering that, designed thirteen public gardens from 1935 to 1937, including Casa Forte Square, his first garden design. As the garden is perishable and renewable, according to The Florence Charter, due to all the physical and biological dynamics, the lack of conservation causes its degradation. Thus, this article presents the historiography of Casa Forte square to subsidize effective conservation actions.

KEYWORDS: Art. Cultural heritage preservation. Modern garden. 
5. Icomos-IFLA (1971, p 230).

6. Id. (1981).

A noção de jardim histórico foi pela primeira vez discutida em 1971, no I Colloque sur la Conservation et la Restauration des Jardins Historiques em Fontainebleau. Nas recomendações finais do colóquio foi adotada a seguinte definição: "um jardim histórico é uma composição arquitetônica e vegetal que apresenta do ponto de vista da história e da arte um interesse público". 5

Durante o colóquio, o arquiteto paisagista belga René Pechère, em sua conferência "La restauration des jardins historiques et la philosophie du colloque", expressou que poderiam ser considerados jardins históricos os que possuíssem valor e geralmente aceitos como parte do patrimônio cultural. Segundo Pechère, estes jardins podiam ser regulares ou irregulares, clássicos, barrocos, românticos, modernos ou paisagísticos; e sendo exemplares de um trabalho original, são considerados "monumentos vivos", definição adotada pela Carta de Florença de 1981.6

Ao longo dos anos, estudiosos de jardins históricos foram criando suas definições e, dentre elas, destacam-se a da paisagista Carmen Añón Feliú e a do arquiteto Géza Hajós. Carmen Añón Feliú assume que um jardim histórico:

é uma criação espacial no qual elementos arquitetônicos e elementos naturais formam uma unidade inseparável, constituindo um importante documento histórico, uma forma de grande valor estético, uma expressão de inquestionáveis características espirituais??

Esta definição foi defendida no I Congreso del Patrimonio Histórico de 1979, da Asociación de Defensa Ecológica y del Patrimonio Histórico-Artístico. Para Géza Hajós, um "jardim histórico é um monumento, uma obra criada com construção e material vegetal, é uma concentração artificial e artística de uma paisagem cultural". ${ }^{8}$

Podemos perceber nas definições de Carmen Añón Feliú e Géza Hajós que o jardim histórico constitui um documento único, com seu próprio processo de desenvolvimento e refletindo uma sociedade e uma cultura que o criou, o vive e o mantém. Desta forma, possui poder de evocação ainda mais forte que outros tipos de jardim, a espiritualidade de significados, de lendas e da arte, bem como integra o homem a seu passado, a sua história e a sua cultura.

Ao tratar os jardins históricos como obras de arte, o filósofo Rosario Assunto afirma que "o momento da contemplação não é, como na arquitetura, correlativo
7. Añón Feliú (1993, p. 117118).

8. Hajós (2001, p. 4). 
9. Assunto (1973, p. 17-20).

10. Battisti (1989).

11. De Angelis; De Angelis Neto (2004, p. 38).

12. Sá Carneiro et al. (2012, p. 33-41).

13. Pelegrini (2006, p. 115140).

14. Varine-Bohan (1974). à destinação prática do lugar, mas ao próprio fim para o qual o lugar-jardim foi idealizado e realizado". ${ }^{9}$ Assim, Battisti ${ }^{10}$ estabelece princípios norteadores a respeito dos jardins históricos, expressando que eles são monumentos locais com características da arquitetura e não complementos ou decorações das cidades. Eles possuem valor artístico, histórico, valor enquanto memória e, ainda, valores arquitetônico, ecológico, botânico e social. Para De Angelis e De Angelis Neto, o jardim monumento comporta uma gama considerável de objetivos, e os mais significativos são:

i) valorizar e difundir exemplares significativos de verde histórico; ii) ensinar a ler as diversas tipologias de jardins em suas componentes arquitetônica e vegetal; iii) desenvolver a consciência de respeito pelo ambiente em todas suas manifestações, como patrimônio da coletividade e testemunho cultural; iv) contribuir para conservação dos sítios de interesse histórico, ambiental e cultural. ${ }^{11}$

No âmbito do patrimônio histórico-cultural, a categoria de jardim histórico se fortalece ainda mais com a introdução do conceito de paisagem cultural na reunião do Comitê de Patrimônio Mundial da Unesco em 1992. No referido documento, o jardim está na categoria de paisagens culturais criadas intencionalmente pelo homem. Com essa categoria de patrimônio cultural, os jardins históricos parecem ter encontrado maior respaldo para sua preservação, ${ }^{12}$ garantido assim a manutenção de sua característica como documento cultural e fazendo que ele não seja somente um verde urbano, mas produto de uma arquitetura complexa que teve lugar em um tempo histórico.

A noção de patrimônio cultural se mantém vinculada às de lembrança e memória, categorias basais na esfera das ações patrimoniais, uma vez que os bens culturais são preservados em função dos sentidos que despertam e dos vínculos que mantêm com as identidades culturais. Segundo Pelegrini, ${ }^{13}$ nos recônditos da memória residem aspectos que a população de uma dada localidade reconhece como elementos próprios da sua história, da tipologia do espaço onde vive, das paisagens naturais ou construídas.

Na condição de patrimônio os "bens" têm se vinculado à imputação de valores. Desde a instituição da Convenção do Patrimônio Mundial (1977) as definições dos parâmetros para a identificação dos "bens" de interesse universal têm oscilado entre critérios como raridade, urgência, autenticidade, integridade e universalidade. Na visão de Hugues de Varine-Bohan, ${ }^{14}$ o patrimônio cultural deveria ser abordado da perspectiva de três vetores: (i) conhecimento; (ii) bens culturais e (iii) 
meio ambiente. A maior relevância da abordagem de Varine-Bohan deve-se ao fato de que tais acepções do patrimônio se coadunam às noções de bens naturais e culturais, concatenadas mediante as articulações entre natureza e cultura, haja vista que a própria cultura parece ser concebida pelo autor como a natureza transformada pelo trabalho humano (como é o caso do jardim).

Deste modo, objetivou-se com este artigo tornar públicos a história e os princípios projetuais da Praça de Casa Forte, um jardim histórico, projetado em 1935 pelo artista Roberto Burle Marx, considerado o gênio criador do jardim moderno no Brasil, de forma a subsidiar as ações de conservação.

Ao tratar do modernismo nos jardins de Burle Marx, Siegfried Giedion, em Le Brésil et l'architecture contemporaine, ${ }^{15}$ afirma que o paisagista se pautou em variados critérios e, além de estar estritamente vinculado ao seu tempo, não negligenciou o passado, ou seja, a história do lugar. Outra característica a ser evidenciada é o emprego da vegetação autóctone atrelada a uma reflexão sobre a brasilidade - tão discutida na Semana de Arte Moderna, de 1922.

O conhecimento da rica flora brasileira foi uma prática constante na vida de Burle Marx - que se consolidou no Recife com suas primeiras expedições e, de acordo com Siqueira, ${ }^{16}$ foi de extrema importância, pois ele se recusava a "permanecer nos limites das espécies já conhecidas ou tradicionalmente utilizadas no paisagismo". O profundo conhecimento em fitogeografia que Burle Marx adquiriu durante suas numerosas viagens pelo país foi, segundo Tabacow, ${ }^{17}$ incorporado em seus projetos através do cuidado com as condicionantes bioclimáticas de cada local e o respeito às condições geomorfológicas encontradas na natureza, a fim de proporcionar o bom desenvolvimento das plantas e criar microclimas confortáveis ao usuário.

A visão holística da paisagem fez que Burle Marx, já no início de sua carreira na cidade de Recife, onde permaneceu de dezembro de 1934 a dezembro de 1937, idealizasse o plano de aformoseamento com jardins que obedecessem conscientemente a um objetivo funcional. Assim, neles encontramos sempre a preocupação "hygienica e educativa, subordinada a uma idéa geral de esthetica". ${ }^{18}$ Segundo Siqueira, ${ }^{19}$ o movimento de modernização urbana de Recife (plano de aformoseamentol contou com a simpatia e o apoio dos intelectuais progressistas, artistas, arquitetos, teóricos e escritores, incluindo Gilberto Freyre, Joaquim Cardozo, Clarival do Prado Valladares e Cícero Dias.

A Praça de Casa Forte, juntamente com a Praça Euclides da Cunha (1935), a Praça do Derby (1936), o Conjunto Praça da República e Jardim do Palácio do Campo das Princesas (1936), a Praça Ministro Salgado Filho (1957) e a Praça Faria
15. Giedion (1952, p. 42-43).

16. Siqueira (2017b, p. 93).

17. Tabacow (1996).

18. Cf. Jardins brasileiros... (1936, p. 32).

19. Siqueira (2017a). 
20. Denominação presente no projeto original. Contudo, de agora em diante passaremos a usar a tipologia "praça" quando nos referirmos ao Parque da Casa Forte.

21. Hamerman (1995, p. 156-179).

22. O monumento tinha como motivo exaltar o feito dos heróis da Batalha de Casa Forte - travada entre portugueses e holandeses em 17 de agosto de 1645, na então campina de Casa Forte (até 1911 a área pertencia ao engenho Casa Forte, onde hoje se encontra a Praça de Casa Forte). Possivelmente o estilo art déco do monumento deu-se pelo fato de que "nada marcou mais o cenário arquitetônico das cidades brasileiras entre as décadas de 1930 e 1940 que a arquitetura de tendências art déco [...] O Art déco revelou-se uma linguagem acessível às elites, às classes médias e às classes populares" (Correia, 2008, p. 52-53).

23. Parque da Casa Forte, nos sucessivos: Praça de Casa Forte, como hoje é denominada.

24. Marx (1935, p. 1).

25. A construção do Parque de Casa Forte custou $92.000 \$ 000$ contos de réis.
Neves (1958) - obras projetadas por Burle Marx -, são consideradas patrimônio cultural do Brasil pelo Instituto do Patrimônio Histórico e Artístico Nacional (Iphan), inscritas em 13 de junho de 2017 nos seguintes livros de tombo: Belas Artes, Histórico e Arqueológico, Etnográfico e Paisagístico.

\section{UM PASSEIO PELA HISTÓRIA DA CRIAÇÃO DA PRAÇA DE CASA FORTE}

O Projeto de Ajardinamento do Parque da Casa Forte ${ }^{20}$ foi a primeira experiência de Burle Marx em desenho de jardim público. ${ }^{21}$ Para a execução desse projeto foi necessário desconsiderar o que já existia no parque, fruto da gestão do prefeito Antônio de Góis Cavalcanti (1931/1934), que teve como mentor o jornalista Mário Carneiro do Rego Melo, então secretário do Instituto Arqueológico e Geográfico de Pernambuco e que contou com a participação dos moradores.

Tal projeto foi desenhado em três jardins, já compreendia o arruamento e continha em seu agenciamento passeios em terra batida, bancos, gramado e uma arborização representada por duas espécies de palmeiras: Cocos nucifera (coqueiro) e Livistona chinensis (palmeira-leque-da-china). No centro do jardim foi erguido um

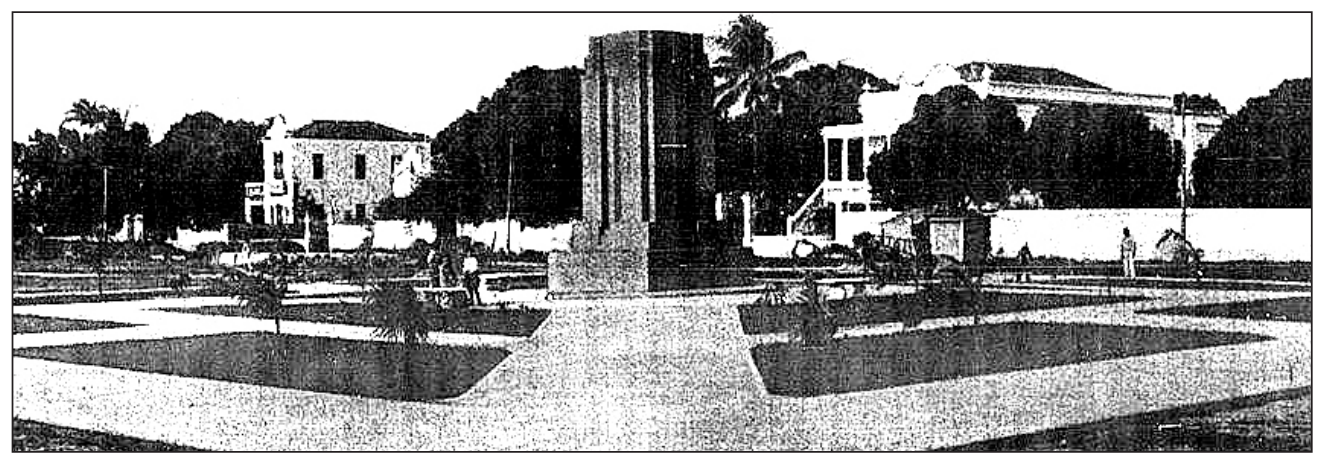

Figura 1 - Parque da Casa Forte com destaque para o monumento evocativo da batalha de Casa Forte, 1935. Fonte: A Noite llustrada (1935, p. 1).

monumento em alvenaria de rigor geométrico e ritmo linear estilo art déco ${ }^{22}$ e em lineamento com a Capela de Nossa Senhora das Necessidades (Figura 1).

No projeto de ajardinamento de Burle Marx, o novo Parque da Casa Forte 23 foi "composto de tres lagos, obedecendo ás fórmas geométricas de maior simplicidade". ${ }^{24}$ Para tanto, a primeira providência do paisagista foi mandar 
demolir o monumento ${ }^{25}$ alegando ser um "inexpressivo bloco de alvenaria com pretensões a monumento em homenagem aos heroes de Casa Forte merecedores, sem duvida, de uma mais digna consagração, pois esse pseudo-monumento sem nenhum valor artístico, não poderá figurar por hypothese alguma um jardim cuidadosamente estudado". ${ }^{26}$

Assim, Burle Marx propõe colocar

um simples monolitho cortado em bôa pedra granitica, obedecendo a uma forma bem justa e definida onde serão collocados além de inscripção commemorativa do grande feito, os nomes de seus heroes, tão ardorosamente defendidos pelos amadores da Historia de Pernambuco $[\ldots]^{27}$

Porém, o monólito nunca foi colocado no jardim.

As fontes de inspiração para Burle Marx idealizar os jardins da Praça de Casa Forte foram: as espécies brasileiras cultivadas nos "jardins Dahlem" e nos "jardins aquáticos de Kew Gardens", os artigos da revista Garten Schönheit e a paisagem do "parque de Dois Irmãos" em Recife 28 laté 1939 denominado de Horto Florestal de Dois (rmãos). Soma-se a esses fatores o conhecimento de ecologia que já possuía desde 1928, quando tinha aulas com o dr. Fernando Rodrigues da Silveira, no Jardim Botânico do Rio de Janeiro.

No parque de Dois Irmãos, Burle Marx encontrou um remanescente de floresta atlântica com seus corpos d'água e pôde observar a diversidade de espécies botânicas. Possivelmente foi nesse fragmento florestal que o paisagista realizou sua primeira expedição para selecionar espécies com potencial paisagístico para compor seus jardins e observar in loco como as plantas se associavam (relações ecológicas de competição), além de ter ido ao sertão pernambucano a fim de conhecer a vegetação da Caatinga para a Praça Euclides da Cunha (1935). As expedições eram necessárias já que, segundo Lauro Borba, "o sr. Burle Marx e elle proprio me confessou ter encontrado em Recife uma unica orientação sobre a nossa flora ornamental" ${ }^{29}$ Essa orientação se refere a um estudo realizado por técnicos da prefeitura e solicitado pelo próprio Lauro Borba, enquanto prefeito do Recife (193019311.

Os jardins de plantas aquáticas de Kew Gardens (Figura 2) foi o ponto de partida para Burle Marx criar os jardins aquáticos da Praça de Casa Forte (Figura 3). As plantas para o "jardim de água vieram do Jardim Botânico, no Rio". ${ }^{30}$ A relação que Burle Marx tinha com o Jardim Botânico do Rio de Janeiro, por ser fornecedor de "mudas e sementes", 31 possibilitou a vinda de um significativo
26. O monumento foi demolido em 8 de junho de 1935 "com o feito de transformar aquele recanto numa paisagem amazônica" (Melo, 1935a, p. 1; 1935b, p. 1).

27. Marx (1935, p. 12).

28. Id. (1987, p. 71).

29. Borba (1937, p. 2).

30. Cf. Hamerman (1995, p. 168).

31. Cf. Noticiário... (1935, p. 102). 
32. Cf. Jardins brasileiros... (1938, p. 3).

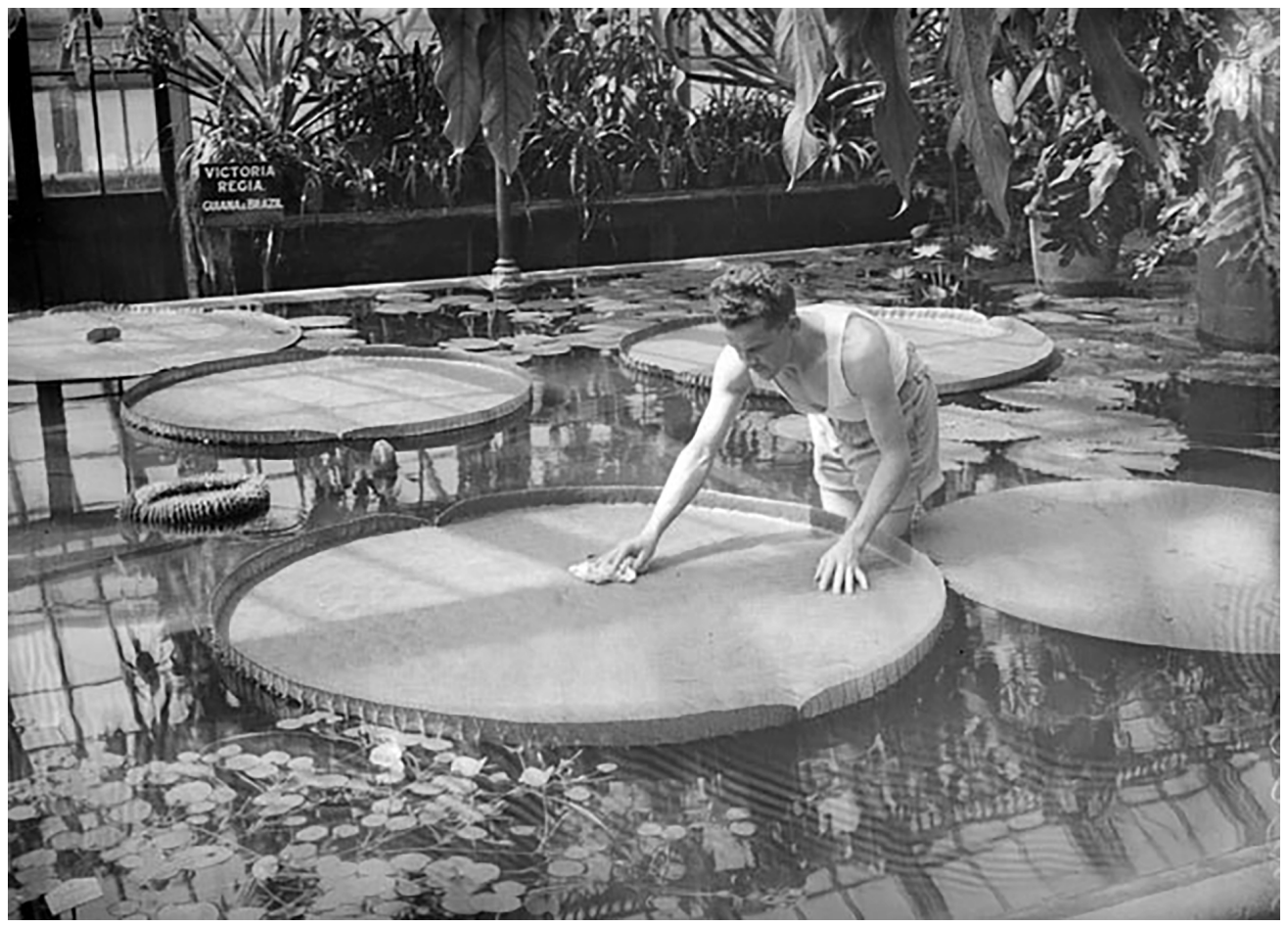

Figura 2 - Jardim aquático de plantas tropicais do Kew Gardens. Destaque para as Victoria amazonica e para as Nymphaea sp., 27 jun. 1935. Acervo do The Telegraph.

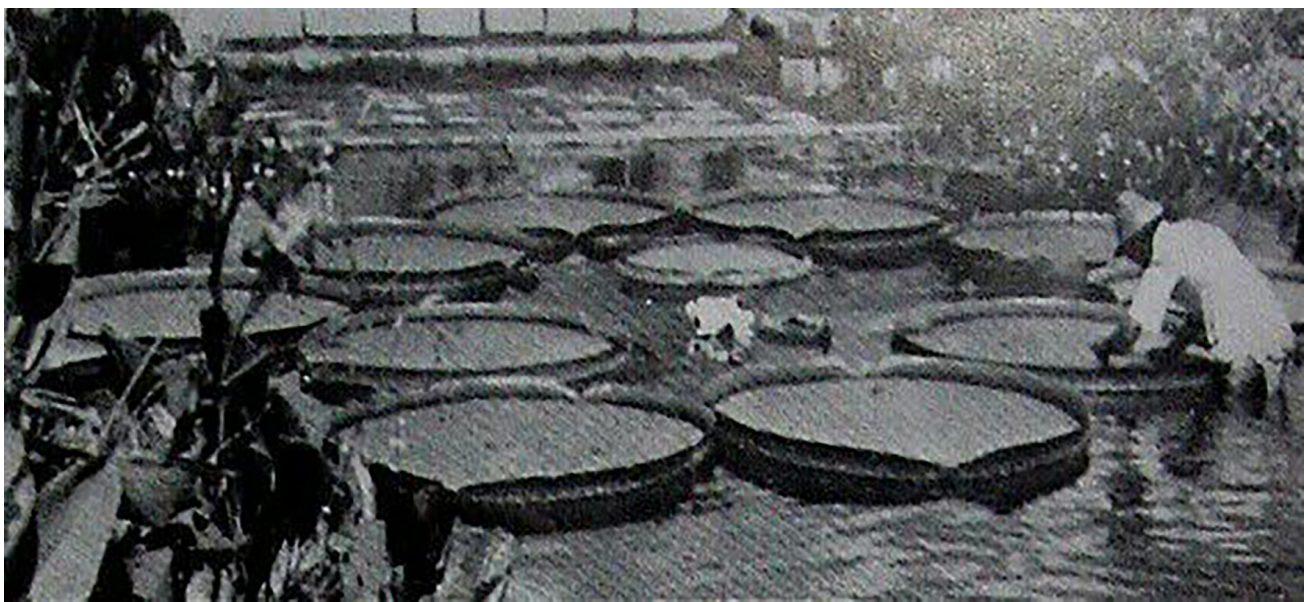

Figura 3 - Praça de Casa Forte. Jardim de plantas nativas. Jardineiro fazendo a manutenção da Victoria amazonica. Fonte: Brazilian flowers (1936, p. 44).

número de indivíduos de várias espécies para os jardins de Recife que ele estava projetando. $\bigcirc$ paisagista também contou com o apoio do dr. Paulo Campos Porto, 
que dirigiu entre os anos de 1934 a 1938 o Instituto de Biologia Vegetal e o Jardim Botânico do Rio de Janeiro, o qual cedeu "varias coleções de plantas raras". ${ }^{32}$

Do Jardim Botânico de Dahlem veio o conhecimento das espécies brasileiras que estavam organizadas por grupos ecológicos conforme a classificação do botânico Heinrich Gustav Adolf Engler. Burle Marx se encantou com "as enormes folhas de gigantescos filodendros, o vistoso colorido das brácteas, das bromeliáceas, inúmeras palmeiras em estufas com 30 m de altura, Victorias-régias com folhas perfeitas, em tanques especiais". ${ }^{33}$

paisagista aprofundou seus conhecimentos à medida que lia os artigos, principalmente sobre a "flora epífita" do Brasil, contidos na revista Garten Schönheit, que também trazia exemplos de "parques e jardins de outros países". ${ }^{34}$

Mesmo o projeto da Praça de Casa Forte sendo considerado por Burle Marx como de "maior simplicidade" por seu traçado, ${ }^{35}$ o que se obteve como resultado foi um sítio de expressão paisagística grandiosa (Figura 4). $\bigcirc$ desenho da Praça de Casa Forte foi direcionado para a educação do olhar do visitante,

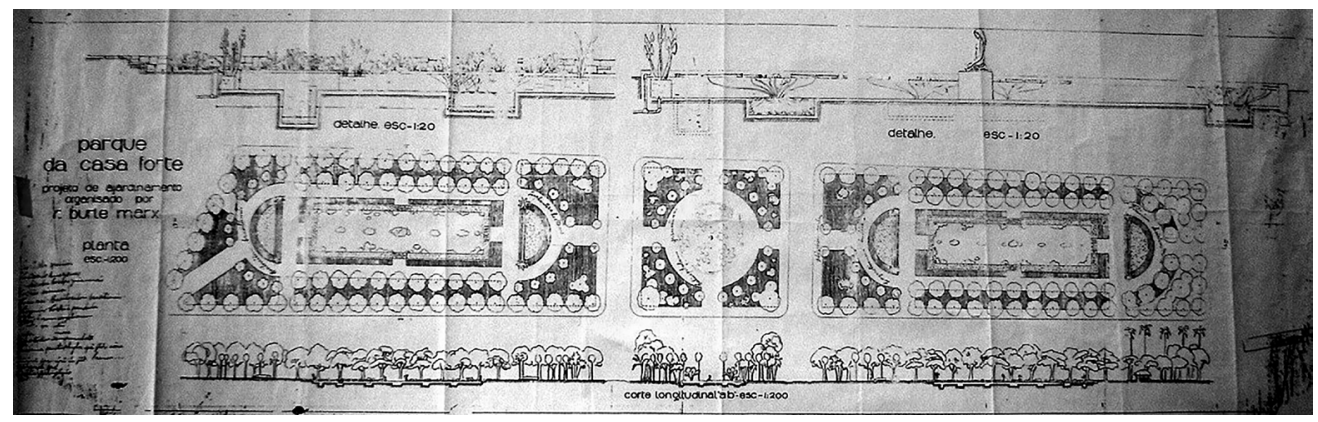

Figura 4 - Projeto do Parque da Casa Forte (Praça de Casa Forte). Escala do projeto: 1:200, s/d. Acervo do Museu da Cidade do Recife.

possibilitando a compreensão de distintos grupos vegetacionais que foram empregados com uma ideia de conjunto.

A primeira parte da praça, primeiro jardim, abrigou uma diversidade de espécies do território brasileiro, por exemplo: "Tajás do Amazonas, aningas, representantes da família das gramíneas, canna fistula, lpê, Jatahyrama, Mulungu', Munguba". ${ }^{36}$ Tal fato, conferiu a esta parte da praça, como é possível ver na Figura 5, um aspecto de exuberância tropical. Além dessas espécies, o paisagista também propôs uma "variedade de plantas aquáticas aos nossos rios e açudes". ${ }^{37}$ As espécies selecionadas nunca antes tinham sido usadas para embelezar um jardim, e essa foi uma maneira de colocar em evidência a paisagem recifense.

A segunda parte da praça, jardim central, Burle Marx dedicou inteiramente às plantas amazônicas. Assim, o paisagista especificou espécies como:
33. Miranda (1992, p. 71).

34. Ibid., loc. cit.

35. Marx (1935, p. 1).

36. Ibid., loc. cit.

37. Ibid., loc. cit. 
38. Ibid., loc. cit.

39. Heliófila: característica das espécies vegetais classificadas em seu grupo ecológico como pioneiras, ou seja, que demandam grande intensidade de luz para o desenvolvimento.

40. Higrófila: característica das espécies que necessitam de grande umidade para seu estabelecimento.

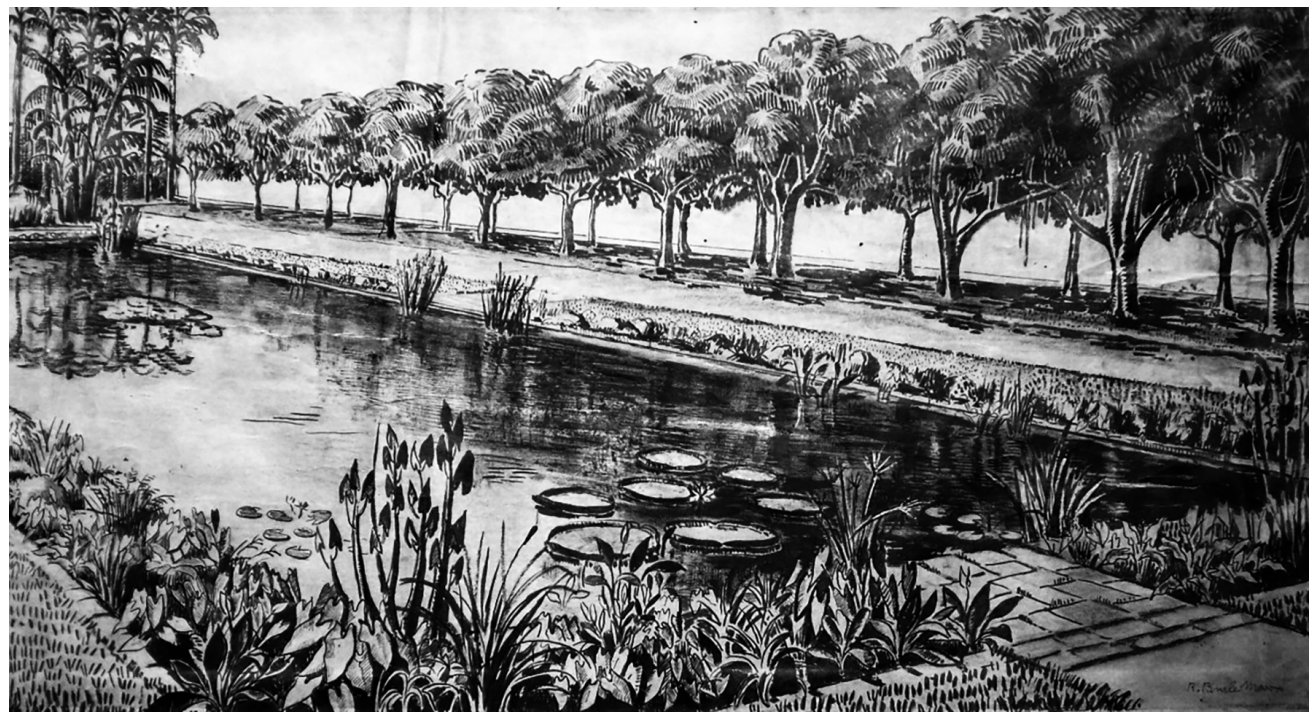

Figura 5 - Desenho de Burle Marx para a Praça de Casa Forte, 1935. Acervo do Centro Cultural Sítio Roberto Burle Marx.

Páos-Mulato lárvore interessante pelo seu feitio definido de troncos em columnata e copas symetricas, de grande effeito decorativo, para jardins architectonicos), tinhorões (que darão a nota colorida ao locall. [...] Nos quatros ângulos existirão blocos de palmeiras taes como: scheellias, assahys, mumbacas, bacabas, urucurys, jouarys. ${ }^{38}$

Para essa parte da praça o paisagisła propõe duas intenções (Figura 6), possivelmente pela indisponibilidade das espécies, já que elas foram solicitadas ao Jardim Botânico do Rio de Janeiro, ou até mesmo pela composição, uma vez que a modificação só ocorre no emprego das palmeiras. Na primeira composição, e por uma questão de escala, a Oenocarpus bacaba (bacaba), por ser uma palmeira de grande porte, assumiu a função de pórtico nos dois eixos, seguida pela Mauritia flexuosa (buriti). Já na segunda composição, o Euterpe edulis (açaí), pelo modo de desenvolvimento em touceiras e pela volumetria que assumiria, foi empregado sem associação com outras espécies de palmeiras, e se destaca na composição com a função de pórtico. $\bigcirc$ uso dessa espécie dá à praça uma paisagem mais próxima às fitofisionomias encontradas na Amazônia.

O jardim central chama atenção porque nele Burle Marx recria o microclima amazônico em atendimento às exigências ambientais do Calycophyllum spruceanum (pau-mulato). Por serem indivíduos de uma espécie heliófila ${ }^{39}$ e higrófila, ${ }^{40}$ o paisagista os distribuiu no centro do jardim, de forma a não sofrerem sombreamento permanente por indivíduos de outras espécies. 
Além disso, indica o uso de palmeiras como Euterpe edulis (açaí), Oenocarpus bacaba (bacaba) e Mauritia flexuosa (buriti) de modo a favorecer um ambiente úmido.

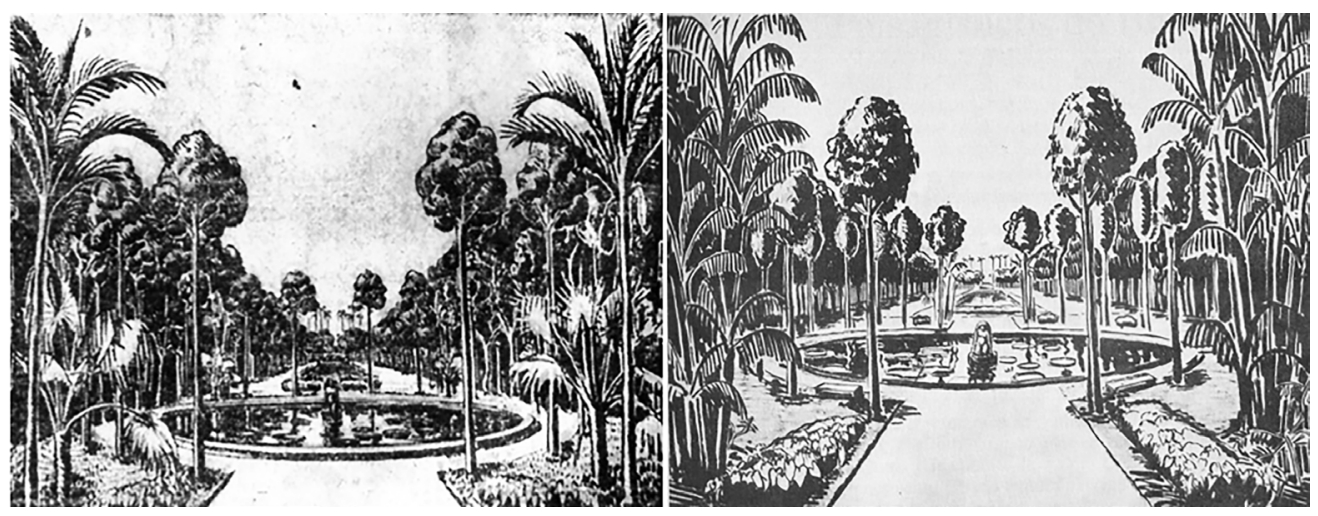

Figura 6 - Duas intenções projetuais para o jardim de plantas amazônicas. No lado esquerdo, presença de duas espécies de palmeiras: Oenocarpus bacaba e Mauritia flexuosa; no lado direito, apenas os blocos de Euterpe edulis com o canteiro de Caladium bicolor. Fonte: Marx (1935, p. 1; 1987, p. 45).

A criação de um jardim dedicado à Amazônia causou na época uma inquietação na população, já que os principais jornais divulgavam que Burle Marx iria criar a Floresta Amazônica em Recife e devolver à cidade a selva. Em defesa de seu projeto, Marx explica: "Quanto á floresta amazonica nunca tivemos pretensão de creal-a. [...], mas apenas um jardim d'agua, onde se procurou lançar mão de elementos colhidos na flora riquíssima daquela região". ${ }^{41}$

A terceira parte da praça, terceiro jardim, foi destinada às espécies tropicais de outros continentes, mas que possuíssem afinidade com a paisagem recifense, e teve como destaque na composição as seguintes espécies: "loctus, Cyperus Papyrus, Lympheas Zamzibarienses, Canna Indica, a Salla Aethiopica, o Crinum Powell, a Strelitzia e algumas Musaceaes, o Páo-teka, os Flamboyants, Acacias diversas". 42 Com essas espécies, o jardim passa a contar "com arvores de grande porte, de folhagens exuberantes e de florações intensas, onde serão encontrados em associação, a sombra que nos é tão necessária e um meio educativo, subordinados a uma idéa geral de esthetica", ${ }^{43}$ como pode ser visto na Figura 7. Para tanto, Burle Marx passa a importar espécies da Alemanha, o que também ocorreu durante a reforma do Jardim do Palácio do Campo das Princesas (1936-1937).

Os registros que hoje se têm da Praça de Casa Forte (projeto original, croquis, desenhos, fotografias e depoimentos) nos levam a compreender que,
41. Marx (1935, p. 1)
42. Ibid., loc. cit
43. Ibid., loc. cit. 


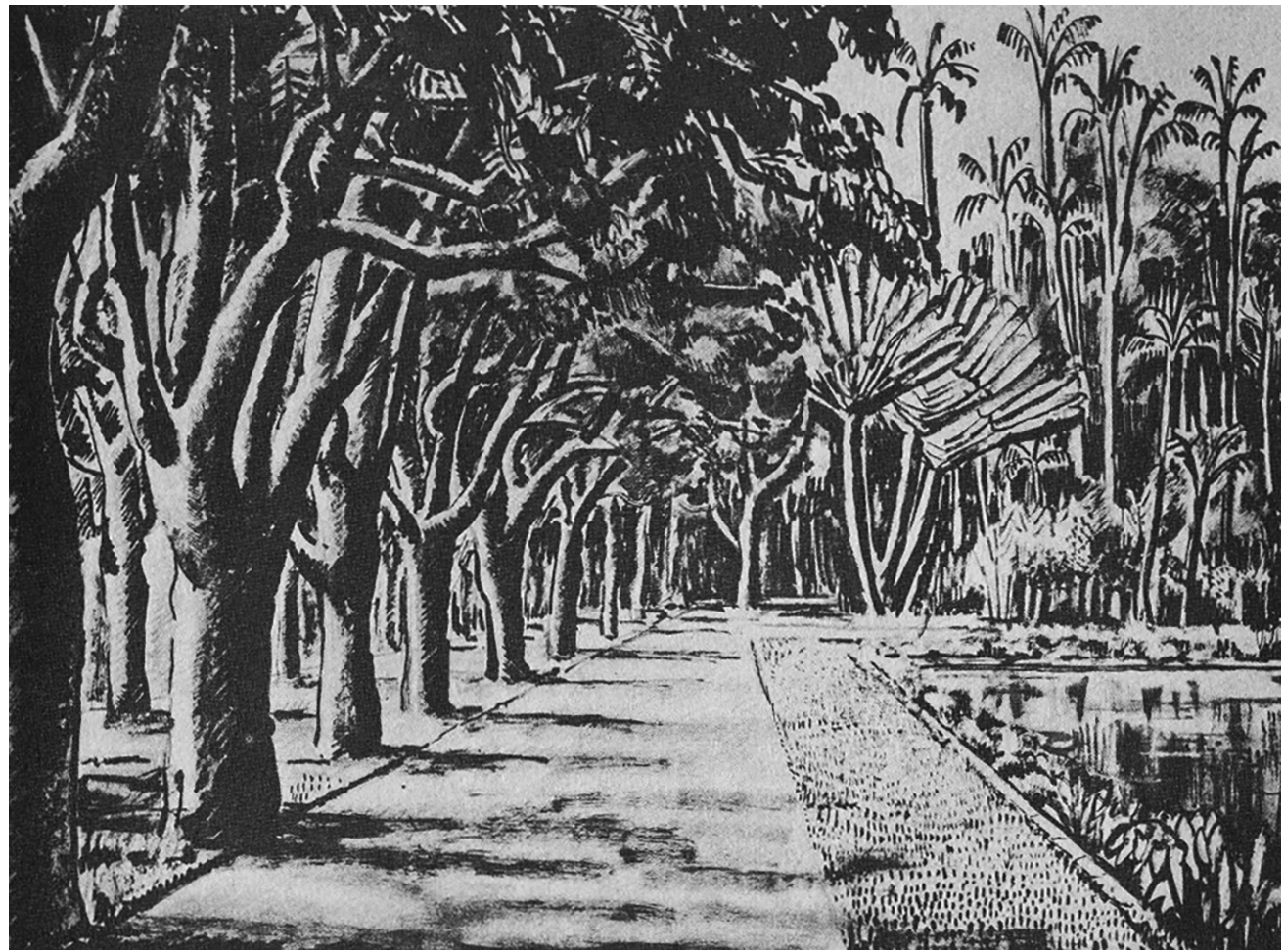

Figura 7 - Desenho de Burle Marx para a Praça de Casa Forte, 1935. Composição do jardim de plantas exóticas. Fonte: Marx (1935, p. 1).

além de paisagista, Burle Marx também foi botânico. A disposição das espécies vegetais respeitando os aspectos fitossociológicos foi o grande ponto para o sucesso do projeto. Outra evidência de seu amplo conhecimento botânico está nos detalhes das jardineiras - de plantas aquáticas e terrestres - onde o paisagista especifica as dimensões e o tipo de substrato necessários para o estabelecimento das espécies.

Os espelhos d'água, componentes de força do projeto, deixam de ser considerados como elementos capazes de "reflectir o jardim circundante, ou para effeitos de repuchos" e passam a ser um "meio capaz de permittir a cultura de uma infindável variedade de plantas". ${ }^{44}$

Com base na fotointerpretação - para a identificação taxonômica dos espécimes presentes nos desenhos de Burle Marx e nas fotografias das décadas de 1930 e 1940 - e na compilação das espécies que constam na planta baixa do projeto original, nos discursos de Burle Marx e do engenheiro e poeta Joaquim Cardozo, assim como nos relatos dos chefes de governo, foi possível chegar à paleta vegetal empregada e/ou intencionada por Burle Marx para a 
Praça de Casa Forte, bem como o local de plantio de alguns indivíduos. Desta forma, identificaram-se 57 espécies distribuídas em 52 gêneros e 27 famílias botânicas. Portanto, entende-se que a Praça de Casa Forte se configurou como um sítio que abrigou uma diversidade florística significativa (Tabela 1).

Tabela 1 - Paleta vegetal histórica da Praça de Casa Forte.

\begin{tabular}{|c|c|c|c|}
\hline Família/Espécie & Nome popular & Extrato & Domínio fitogeográfico* \\
\hline \multicolumn{4}{|l|}{ ALISMATACEAE } \\
\hline Limnocharis flava & Mureré & Herbáceo & $\begin{array}{l}\text { Amazônia, Caatinga, Mata Atlân- } \\
\text { tica }\end{array}$ \\
\hline \multicolumn{4}{|l|}{ AMARYLLIDACEAE } \\
\hline Crinum $\times$ powelli & Crinum & Herbáceo & África \\
\hline \multicolumn{4}{|l|}{ ARACEAE } \\
\hline Alocasia macrorrhizos & Taioba & Herbáceo & - \\
\hline Anthurium amnicola & Antúrio & Herbáceo & Venezuela \\
\hline Caladium bicolor & Caladio & Herbáceo & $\begin{array}{l}\text { Amazônia; Cerrado; Mata Atlânti- } \\
\text { ca; Caatinga }\end{array}$ \\
\hline Caladium lindenii & Malanga & Herbáceo & Colômbia \\
\hline Montrichardia linifera & Aninga & Herbáceo & $\begin{array}{l}\text { Amazônia; Caatinga; Mata Atlân- } \\
\text { tica }\end{array}$ \\
\hline Zantedeschia aethiopica & Copo-de-leite & Herbáceo & África \\
\hline \multicolumn{4}{|l|}{ ARECACEAE } \\
\hline Acrocomia intumescens & Macaibeira & Palmeira & Mata Atlântica \\
\hline Astrocaryum gynacanthum & Mumbacas & Palmeira & Amazônia \\
\hline Aistrocaryum jauari & Jaurari & Palmeira & Amazônia \\
\hline Euterpe edulis & Açaí & Palmeira & Mata Atlântica; Cerrado \\
\hline Mauritia flexuosa & Buriti & Palmeira & Amazônia; Caatinga; Cerrado \\
\hline Oenocarpus bacaba & Bacaba & Palmeira & Amazônia \\
\hline Syagrus coronata & Uricuri & Palmeira & Caatinga; Cerrado \\
\hline \multicolumn{4}{|l|}{ BIGNONIACEAE } \\
\hline Handroanthus heptaphyllus & lpê-roxo & Arbóreo & Cerrado; Mata Atlântica \\
\hline Spathodea campanulata & Espatódea & Arbóreo & África \\
\hline Zeyheria sp. & Ipê-branco & Arbóreo & - \\
\hline \multicolumn{4}{|l|}{ CANNACEAE } \\
\hline Canna indica & Cana-da-índia & Herbáceo & $\begin{array}{l}\text { Amazônia; Caatinga, Cerrado, } \\
\text { Mata Atlântica, Pantanal }\end{array}$ \\
\hline \multicolumn{4}{|l|}{ CLUSIACEAE } \\
\hline
\end{tabular}




\begin{tabular}{|c|c|c|c|}
\hline Clusia sp. & & Herbáceo & - \\
\hline \multicolumn{4}{|l|}{ CONVOLVULACEAE } \\
\hline Evolvulus pusillus & Orvalho & Herbáceo & Mata Atlântica; Cerrado \\
\hline \multicolumn{4}{|l|}{ CYPERACEAE } \\
\hline Cyperus papyrus & Papiro & Herbáceo & Mata Atlântica; Pantanal \\
\hline \multicolumn{4}{|l|}{ FABACEAE } \\
\hline Acacia sp. & Acacias & Arbóreo & - \\
\hline Cassia ferruginea & Chuva-de-ouro & Arbóreo & $\begin{array}{l}\text { Caatinga; Cerrado; Mata } \\
\text { Atlântica }\end{array}$ \\
\hline Cassia grandis & Cássia-grande & Arbóreo & $\begin{array}{l}\text { Amazônia; Cerrado; Mata Atlânti- } \\
\text { ca; Pantanal }\end{array}$ \\
\hline Clitoria fairchildiana & Sombreiro & Arbóreo & Mata Atlântica; Caatinga \\
\hline Delonix regia & Flamboyant & Arbóreo & Madagascar \\
\hline Erythrina velutina & Mulungu & Arbóreo & $\begin{array}{l}\text { Amazônia; Mata Atlântica; Caa- } \\
\text { tinga; Cerrado, }\end{array}$ \\
\hline Hymenaea sp. & Jatobá & Arbóreo & - \\
\hline $\begin{array}{l}\text { Libidibia ferrea var. leiosta- } \\
\text { chya }\end{array}$ & Pau-ferro & Arbóreo & Mata Atlântica; Pantanal \\
\hline Parkia pendula & Visgueiro & Arbóreo & Amazônia, Mata Atlântica \\
\hline Peltophorum dubium & Cana-fistula & Arbóreo & $\begin{array}{l}\text { Caatinga; Cerrado; Mata Atlânti- } \\
\text { ca; Pantanal }\end{array}$ \\
\hline Peltophorum vogelianum & Farinha-seca & Arbóreo & $\begin{array}{l}\text { Caatinga; Cerrado; Mata Attânti- } \\
\text { ca; Pantanal }\end{array}$ \\
\hline Schizolobium amazonicum & Guapuruvu & Arbóreo & $\begin{array}{l}\text { Brasil; Bolívia; Colômbia; Costa } \\
\text { Rica; Equador; Honduras; Méxi- } \\
\text { co; Peru }\end{array}$ \\
\hline Senna siamea & Cássia-amarela & Arbóreo & $\begin{array}{l}\text { Amazônia; Caatinga; Cerrado; } \\
\text { Mata Atlântica }\end{array}$ \\
\hline \multicolumn{4}{|l|}{ HELICONIACEAE } \\
\hline Heliconia psittacorum & Paquevira & Herbáceo & $\begin{array}{l}\text { Amazônia; Caatinga; Mata Atlân- } \\
\text { tica; Cerrado; Pantanal }\end{array}$ \\
\hline \multicolumn{4}{|l|}{ HERNANDIACEAE } \\
\hline Hernandia sonora & Ventosa & Arbóreo & Amazônia \\
\hline \multicolumn{4}{|l|}{ JUNCACEAE } \\
\hline Juncus effusus & Junco & Herbáceo & $\begin{array}{l}\text { Caatinga; Cerrado; Mata Atlânti- } \\
\text { ca; Pampa }\end{array}$ \\
\hline \multicolumn{4}{|l|}{ LAMIACEAE } \\
\hline Tectona grandis & Pau-teca & Arbóreo & Ásia \\
\hline \multicolumn{4}{|l|}{ LYTHRACEAE } \\
\hline Lagerstroemia indica & Rosedá & Arbóreo & China; Japão \\
\hline
\end{tabular}




\begin{tabular}{|c|c|c|c|}
\hline \multicolumn{4}{|l|}{ MALVACEAE } \\
\hline Basiloxylon brasiliensis & Pau-rei & Arbóreo & Mata Atlântica \\
\hline Ceiba speciosa & Paineira & Arbóreo & $\begin{array}{l}\text { Amazônia; Caatinga; Cerrado; } \\
\text { Mata Atlântica }\end{array}$ \\
\hline Pachira aquatica & Munguba & Arbóreo & Amazônia \\
\hline \multicolumn{4}{|l|}{ MALPIGHIACEAE } \\
\hline Lophanthera lactescens & Lanterneira & Arbóreo & Amazônia \\
\hline \multicolumn{4}{|l|}{ MARANTACEAE } \\
\hline Thalia geniculata & Talia & Herbáceo & $\begin{array}{l}\text { Amazônia; Caatinga; Cerrado; } \\
\text { Mata Atlântica; Pampas; Pantanal }\end{array}$ \\
\hline \multicolumn{4}{|l|}{ MELIACEAE } \\
\hline Carapa guianensis & Andiroba & Arbóreo & Amazônia \\
\hline \multicolumn{4}{|l|}{ MUSACEAE } \\
\hline Musaceae & Musaceas & Herbáceo & - \\
\hline \multicolumn{4}{|l|}{ NELUMBONACEAE } \\
\hline Nelumbo nucifera & Lótus & Herbáceo & Ásia \\
\hline \multicolumn{4}{|l|}{ NYMPHAEACEAE } \\
\hline Nymphaea zanzibariensis & Ninfeia & Herbáceo & Ásia \\
\hline Victoria amazonica & Vitória-régia & Herbáceo & Amazônia; Pantanal \\
\hline \multicolumn{4}{|l|}{ RUBIACEAE } \\
\hline Calycophyllum spruceanum & Pau-mulato & Arbóreo & Amazônia \\
\hline \multicolumn{4}{|c|}{ SAPINDACEAE } \\
\hline Filicium decipiens & Felício & Arbóreo & Índia; Sri Lanka \\
\hline \multicolumn{4}{|l|}{ STRELITZIACEAE } \\
\hline $\begin{array}{l}\text { Ravenala madagascarien- } \\
\text { sis }\end{array}$ & Ravenala & Arbóreo & Madagascar \\
\hline Strelitzia sp. & Árvore-do-viajante & Herbáceo & - \\
\hline \multicolumn{4}{|l|}{ TYPHACEAE } \\
\hline Typha angustifolia & Taboa & Herbáceo & Cerrado; Mata Atlântica \\
\hline \multicolumn{4}{|l|}{ ZINGIBERACEAE } \\
\hline Alpinia sp. & Alpínia & Herbáceo & - \\
\hline Etlingera elatior & Bastão-do-imperador & Herbáceo & Malásia \\
\hline
\end{tabular}

* Para determinar o Domínio Fitogeográfico tomou-se por base a Lista de Espécies da Flora de Brasil/Jardim Botânico do Rio de Janeiro e do Missouri Botanical Garden.

Apesar de ter sido na Praça de Casa Forte que se plantou pela primeira vez em praça pública a Victoria amazonica (vitória-régia) - que já foram plantadas mediando "1 m.26 de diametro"45 -, Burle Marx considerava que o aspecto mais 
46. Miranda (1992, p. 71).

47. Cardozo (2009, p. 171176).

48. Leenhardt (2006, p. 28). importante na praça seria o uso de elementos vegetais que ocorriam na paisagem natural da região, e enfatizava o uso da Montrichardia linifera (aninga) da Heliconia psittacorum (paquevira) e da Acrocomia intumescens (macaibeira), esta última "que com seu fuste ventricoso, tão bem caracterizava a paisagem de Olinda e Recife". 46

Joaquim Cardozo, ao lembrar-se dos feitos de seu grande amigo Burle Marx para a Praça de Casa Forte, reforçou a relevância desse projeto para a época, dizendo ter sido ali que, pela primeira vez em Recife, plantaram-se o Calycophyllum spruceanum (pau-mulato), a Libidibia ferrea var. leiostachya (pau-ferro) e o Basiloxylon brasiliensis (pau-rei). Além dessas árvores, a paisagem da praça era composta de Ceiba sp., Eichornia crassipes (baronesa), várias espécies de tabicas de Juncus sp. (junco), Clusia sp. (clusia) e Nymphaea sp. (ninfeia) ${ }^{47}$ (Figura 8).

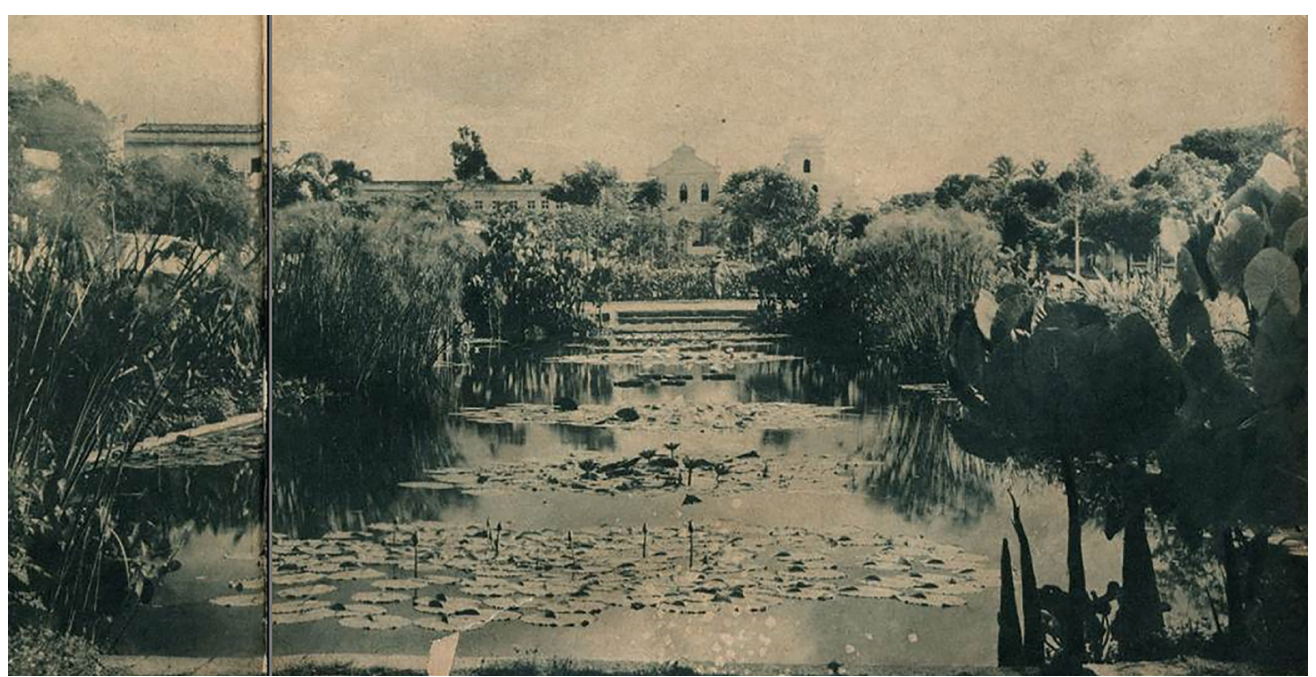

Figura 8 - Praça de Casa Forte, 1939. Em primeiro plano o jardim de plantas nativas, com destaque para a Montrichardia linifera, Nymphaea zanzibariensis e Cyperus papyrus. Fonte: Pernambuco... (1939, p. 6-7).

Mesmo diante do vasto repertório florístico de espécies arbóreas e palmeiras, a vegetação herbácea, tanto aquática quanto terrestre, empregada nos lagos, canteiros e jardineiras, também merece destaque por sua diversidade e abrangência geográfica. Conforme Jacques Leenhardt, "o domínio das superfícies aquáticas é, sem dúvida, um dos segredos de Burle Marx". ${ }^{48}$ Nos lagos dos jardins (Figuras 9 e 10) Burle Marx usa as bordas para introduzir espécies herbáceas terrestres e paludosas que, além de mostrarem a riqueza florística, possuem também, segundo Leenhardt, a função de quebrar a linearidade de suas margens. 


\begin{abstract}
do espelho d'agua de plantas nativas, no centro a Victoria amazonica, fim da década de 1930. Fotografia: Juventino Gomes. Acervo da Fundação Joaquim Nabuco.
\end{abstract}

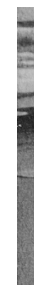

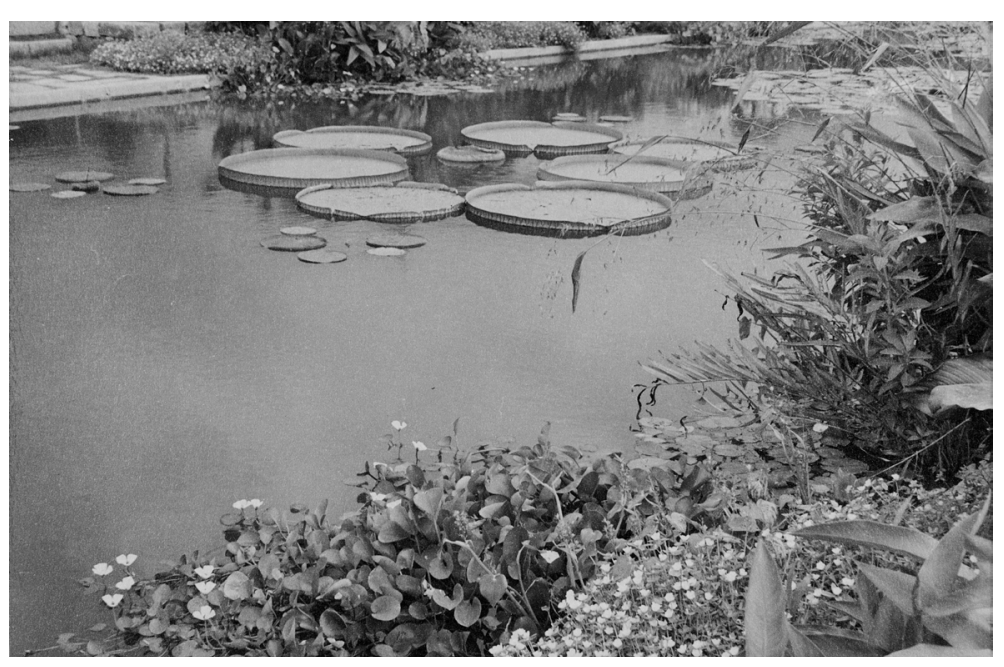

49. Dourado (2000, p. 202).

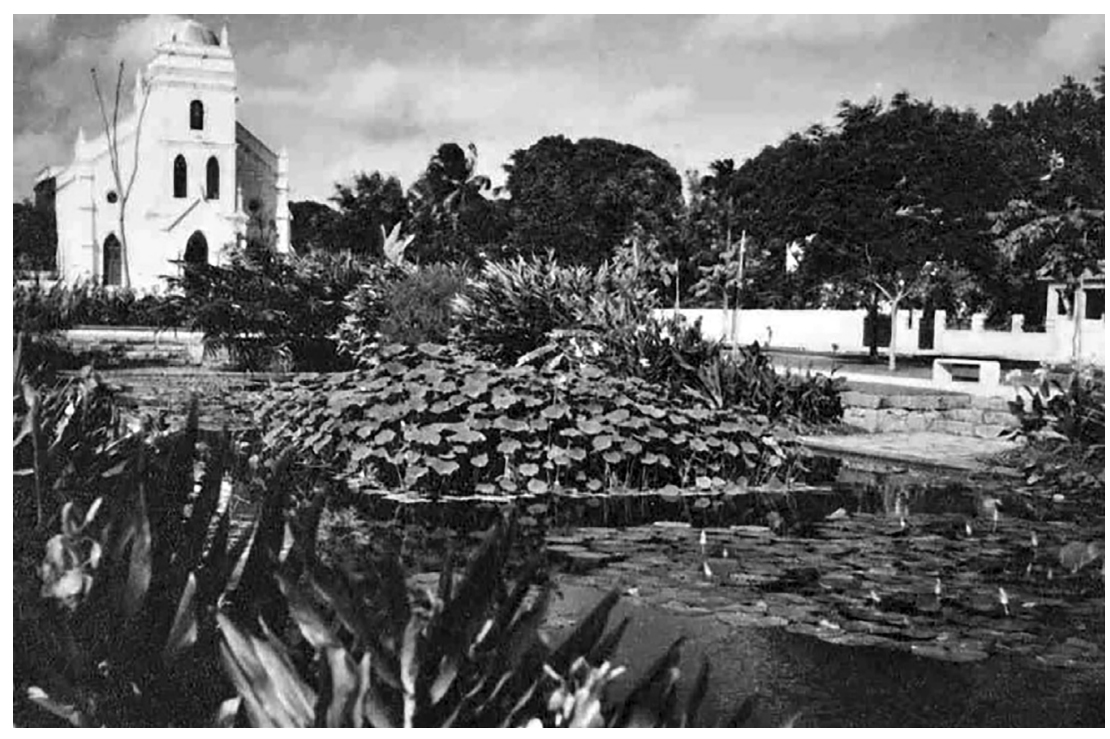

Figura 10 - Detalhes do espelho d'agua de plantas exóticas, no centro Nelumbo nucifera, fim da década de 1930. Fotografia: Benício WhaHey Dias. Acervo da Fundação Joaquim Nabuco.

Além da quebra da linearidade apresentada por Leenhardt, outro aspecto presente na praça são os espaços centrípetos, onde a luz natural incide diretamente no centro de cada lago (iluminação zenital). Conforme Dourado, 49 espaços centrípetos conduzem "a atenção dos observadores da periferia ao centro dos ambientes. Manipulando contrastes acentuados de luz e sombra e de escalas das massas vegetais". A incidência direta de luminosidade nos lagos, além da questão artística, também tem a função de garantir as condições ambientais favoráveis para o estabelecimento da vegetação herbácea, seja ela aquática ou terrestre, que demanda um ambiente de pleno sol a meia sombra. Desta forma, Burle Marx respeita a exigência ecológica de cada espécie em prol da condição artística que um jardim exige. 

conseguir o transplante e o plantio de indivíduos arbóreos adultos, sendo a maioria deles, a exemplo do Calycophyllum spruceanum (pau-mulato) e do Schizolobium amazonicum (guapuruvu), trazidos do Jardim Botânico do Rio de Janeiro (Figura 11 ).

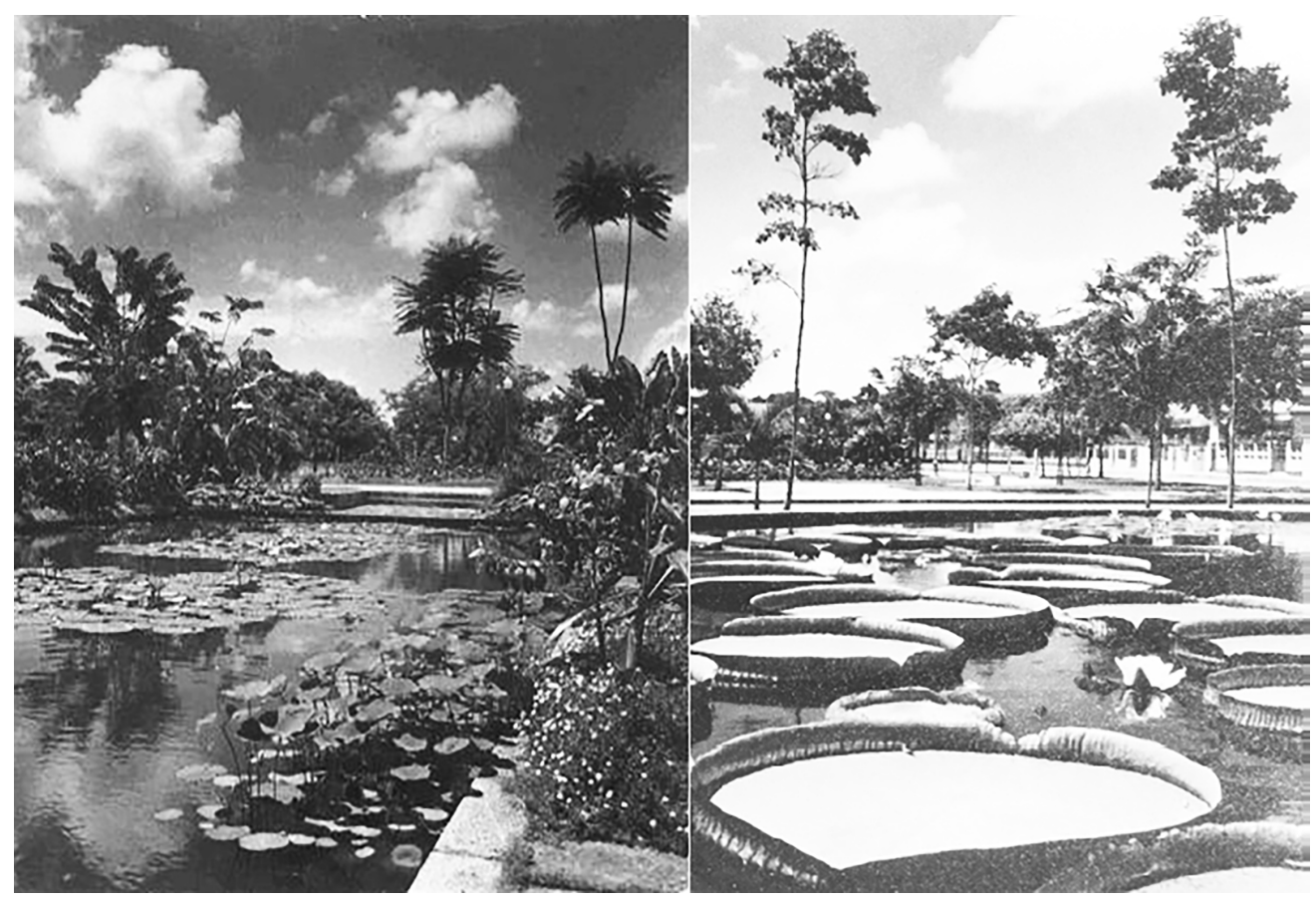

Figura 11 - Praça de Casa Forte. Observa-se o plantio de espécies arbóreas já com porte adulto, no lado esquerdo indivíduos de Schizolobium amazonicum e no lado direito Calycophyllum spruceanum, fim da década de 1930. Acervo da Fundação Joaquim Nabuco.

Com a preocupação de que o projeto fosse executado pelos jardineiros conforme tinha idealizado, Burle Marx sempre fez questão de externar suas ideias, tanto por meio de palavras quanto por seus desenhos a bico de pena, o que ocorreu frequentemente nos jornais locais. Em seus desenhos o paisagista destacou a diversidade de espécies vegetais, enfatizando as características morfológicas externas, assim como as exigências ecológicas. Mesmo possuindo vasto repertório botânico, Burle Marx, em seis áreas da Praça de Casa Forte, optou por valorizar agrupamentos de indivíduos de mesma espécie, pois segundo ele:

as associações de plantas diversas criam ambientes harmônicos. Outras vezes a beleza se obtém pela repetição da mesma espécie, formando massas homogêneas. Às vezes o elemento floral se valoriza mais, ao ser percebido com todos os detalhes de sua estrutura. ${ }^{50}$ 
As massas homogêneas, maciço arbóreo, propostas por Burle Marx podem ser vistas na Figura 12. No primeiro jardim da praça temos o Basiloxylon brasiliensis (pau-rei) e a Lophanthera lactescens (lanterneira); no segundo, o Calycophyllum spruceanum (pau-mulato); e na terceira parte, o Schizolobium amazonicum (guapuruvu), a Lagerstroemia indica (rosedá) e o Filicium decipiens (felício).

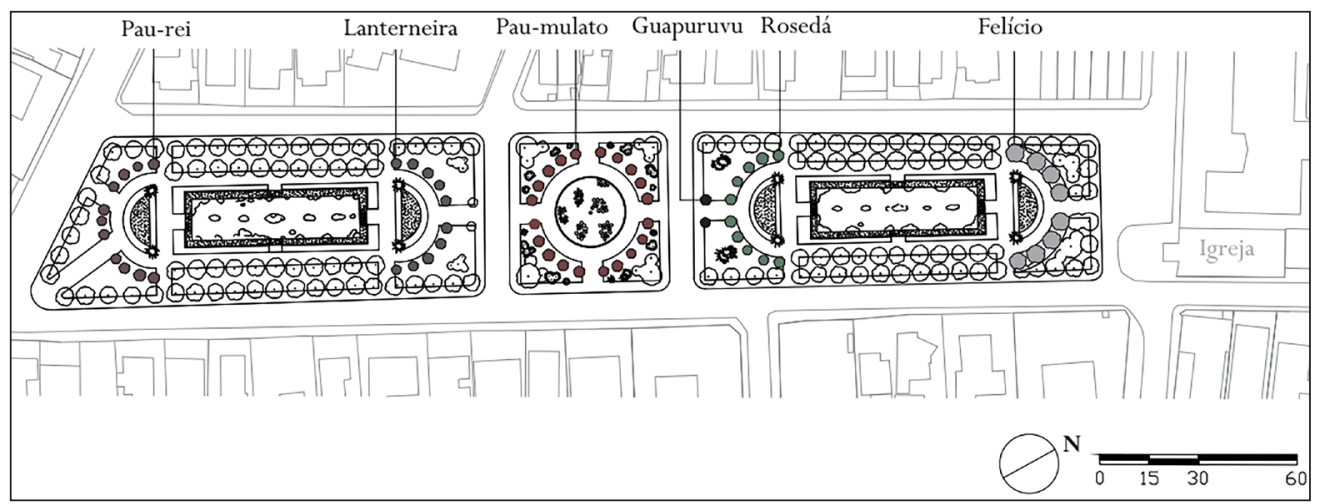

Figura 12 - Praça de Casa Forte. Grupos de espécies conforme especificado no projeto original, 1935. Fonte: Silva (2017, p. 144).

Contudo, ao identificar os espécimes presentes nas fotografias do final dos anos 1930 e início de 1940, constatou-se que Burle Marx realizou mudanças no tocante às espécies durante a execução do projeto (substituição, introdução e local de plantio), o que ocasionou um novo arranjo paisagístico.

No jardim de plantas nativas ocorreu a substituição da Lophanthera lactescens (lanterneira) por Cassia grandis (cássia-grande), que também foi plantada em outras áreas, como na saída (em sentido ao jardim de plantas amazônicas), assumindo a conotação de pórtico, e nas fileiras duplas. Os registros históricos revelaram também o local de plantio dos indivíduos de Carapa guianensis (andiroba), que consta na lista de vegetação do projeto original, mas que Burle Marx não indicou em planta baixa (Figura 13).

Das duas intenções de composição idealizadas por Burle Marx para o jardim de plantas amazônicas, a que prevaleceu (em parte) foi aquela na qual havia Oenocarpus bacaba (bacaba) e a Mauritia flexuosa (buriti), porém só os indivíduos de Oenocarpus bacaba foram plantados. Também se percebe o plantio de indivíduos de Clitoria fairchildiana (sombreiro) entre os de Calycophyllum spruceanum (pau-mulato). Possivelmente a introdução dessa espécie, de porte menor que o Calycophyllum spruceanum, se deu pelo fato de garantir um local com temperatura mais amena para o estabelecimento de seus indivíduos. É essa estratificação que se percebe quando se observa as florestas, onde indivíduos de Calycophyllum spruceanum pontuam o dosse ${ }^{51}$ tendo abaixo outras espécies (Figuras 14 e 15).
51. Dossel: "A camada superior da vegetação de uma floresta", segundo Ricklefs (2003, p. 483). 


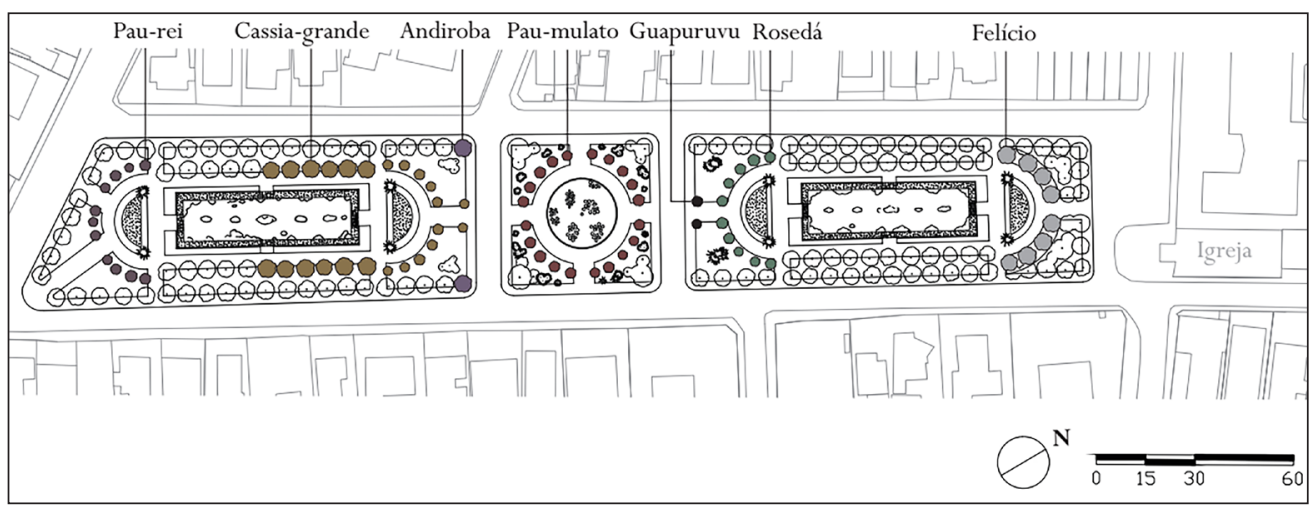

Figura 13 - Praça de Casa Forte. Destaque para a inclusão, no primeiro jardim, das espécies Cassia grandis e Carapa guianensis. Fonte: Silva (2017, p. 145).

Figura 14 - Jardim de plantas amazônicas da Praça de Casa Forte. Veem-se os indivíduos de Mauritia flexuosa, de Calycophyllum spruceanum e de Clitoria fairchildiana, início da década de 1940. Fonte: Acervo da Fundação Joaquim Nabuco.

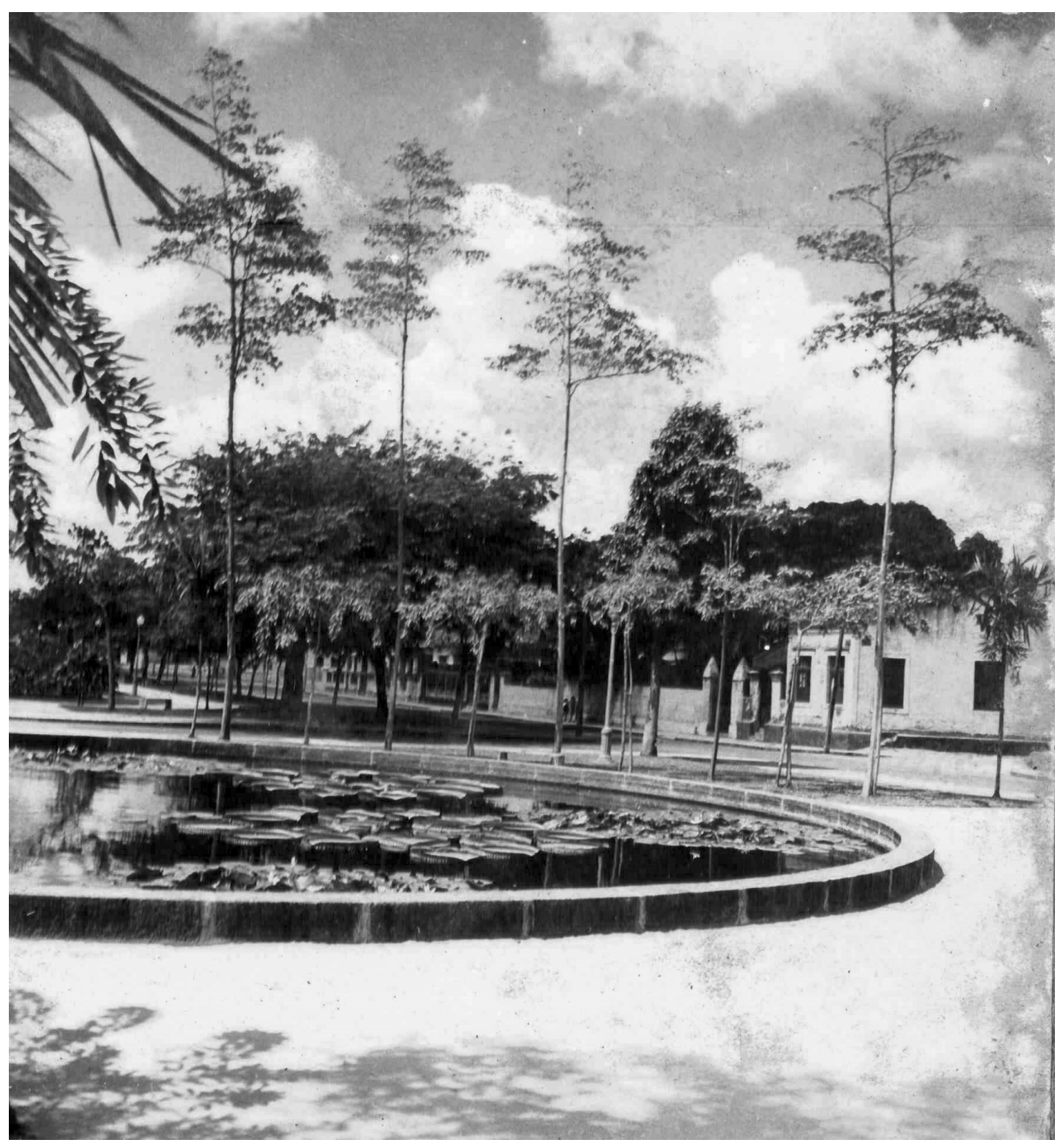




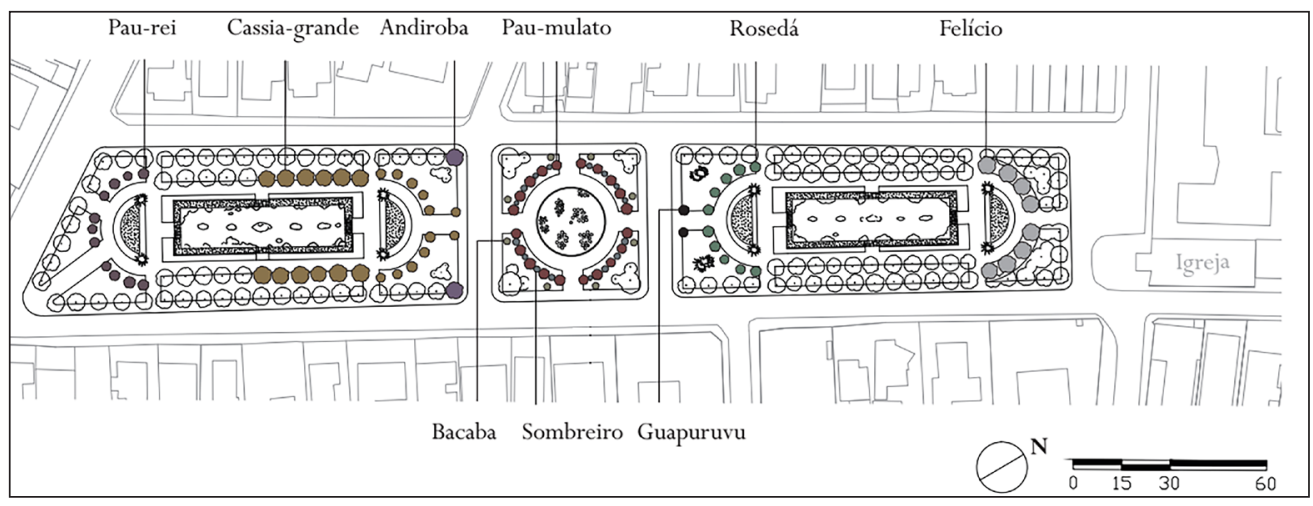

Figura 15 - Praça de Casa Forte. Destaque para a inclusão, no jardim central, das espécies Oenocarpus bacaba e Clitoria fairchildiana. Fonte: Silva (2017, p. 146).

No jardim de plantas exóticas (último à direita), as modificações se deram quanto ao local de plantio do Schizolobium amazonicum (guapuruvu), então substituído por dois indivíduos de Delonix regia (flamboyant). Por sua vez, os dois indivíduos de Schizolobium amazonicum passaram a fazer parte do conjunto de Delonix regia, onde originalmente estava prevista a espécie de Lagerstroemia indica (rosedá). De forma a conseguir simetria entre a vegetação, Burle Marx resolve inserir mais dois indivíduos de Schizolobium amazonicum e de Delonix regia na entrada da praça próxima da igreja (terceiro jardim). Também foi possível identificar, com base nas fotografias de época, o local de plantio de Filicium decipiens (felício) nas fileiras duplas (Figuras 16 e 17).

Com a morte dos Schizolobium amazonicum (guapuruvu), já no final da década de 1940, localizados nos dois extremos do jardim de plantas exóticas, ocorreu o plantio de Delonix regia (flamboyant) e de Caesalpinia peltophoroides (sibipiruna), esta última nativa da Mata Atlântica e do Pantanal mato-grossense, como se pode ver nas Figuras 18, 19 e 20, as duas últimas do final da década de 1940. Também já se percebe a presença do Sabal palmetto (sabal), com porte adulto, possivelmente plantado no início dos anos 1940, porém não se pode atrelar o plantio dessa espécie à Burle Marx, uma vez que ela não fez parte de seu repertório botânico nos projetos de jardins em Recife.

Hoje fazem parte da composição do jardim quatro indivíduos de Couroupita guianensis (abricó-de-macaco). Embora não se tenha encontrado até o momento nenhum registro histórico que pudesse pontuar a época do plantio, dois motivos levam a considerar que a introdução dessa espécie foi indicada por Burle Marx e no fim da década de 1950. O primeiro é que Burle Marx, quando visitava a praça, sempre fazia questão de indicar o manejo e o plantio de espécies; ${ }^{52}$ e o segundo, é que nesta década o paisagista estava projetando os jardins da Praça
52. Em depoimento ao Jornal do Commercio (Obra..., 1998, p. 1) o jardineiro Francisco Lins Cavalcanti, que trabalhou na Praça de Casa Forte por 36 anos (1948-1984) relatou que "Toda vez que Burle Marx visitava a Praça de Casa Forte mandava retirar elementos estranhos ao projeto original. Ele já mandou retirar muita árvore como os pés de flamboyant [...] em volta dos espelhos d'água o paisagista colocou pés de bastão-do-imperador espécie substituída por bastão-do-panamá e liconia”. 
Ministro Salgado Filho (1957) e da Praça Faria Neves (1958), em cuja composição a Couroupita guianensis foi empregada como elemento de destaque.

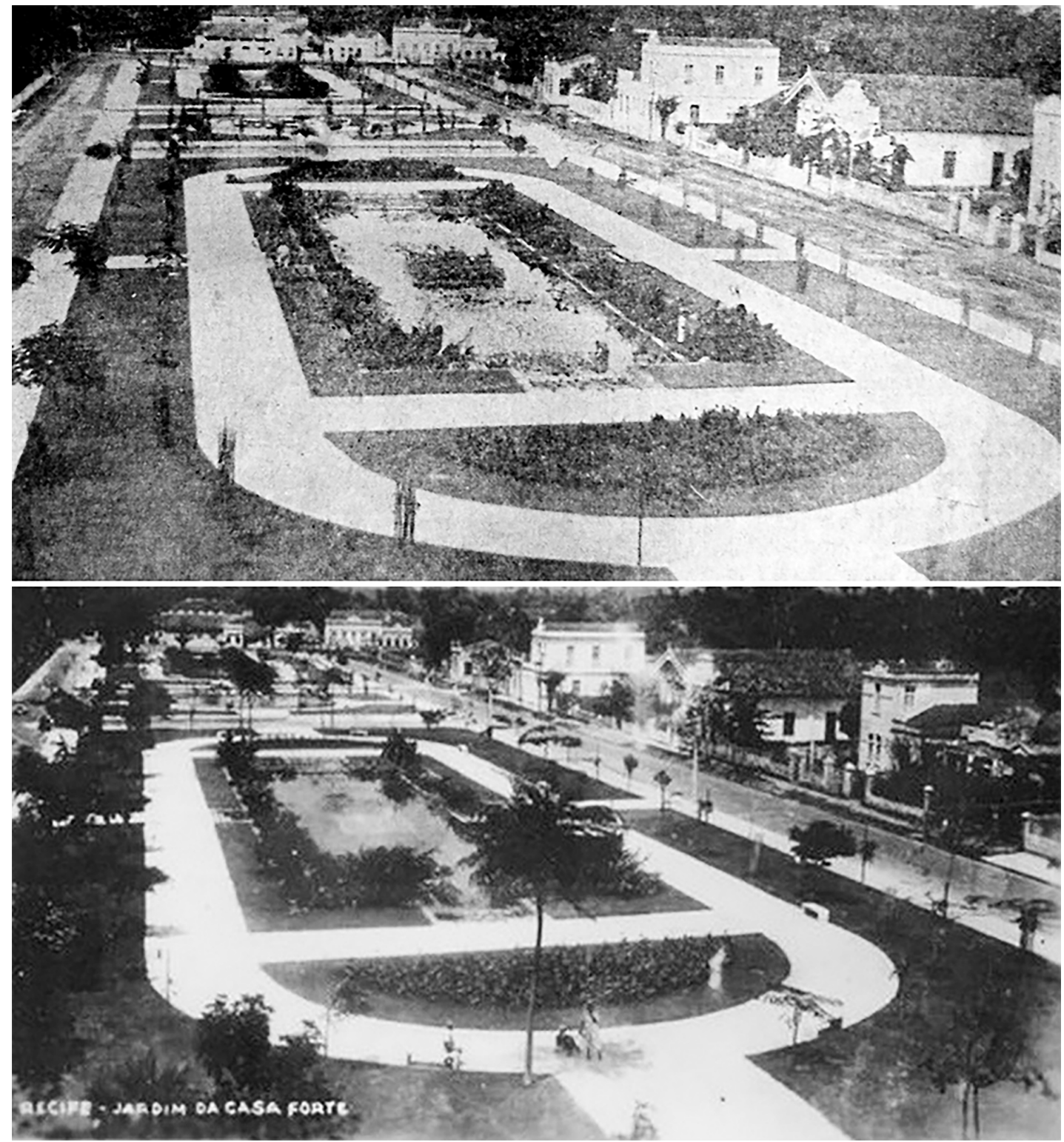

Figura 16 - Dois momentos da execução da Praça de Casa Forte (terceiro jardim). Na primeira figura, de 10 de maio de 1936, vê-se em primeiro plano a parte dedicada à vegetação exótica, tendo ao centro do lago o conjunto de Nelumbo nucifera. Na segunda figura, do início de 1940, pode-se ver indivíduos de Schizolobium amazonicum adultos; e, no semicírculo, uma plantação de Canna indica. Nota-se a ausência do conjunto de Nelumbo nucifera no centro do lago. Fontes: Diario da Manhã (1936, p. 1); e Acervo do Recife de Antigamente. 


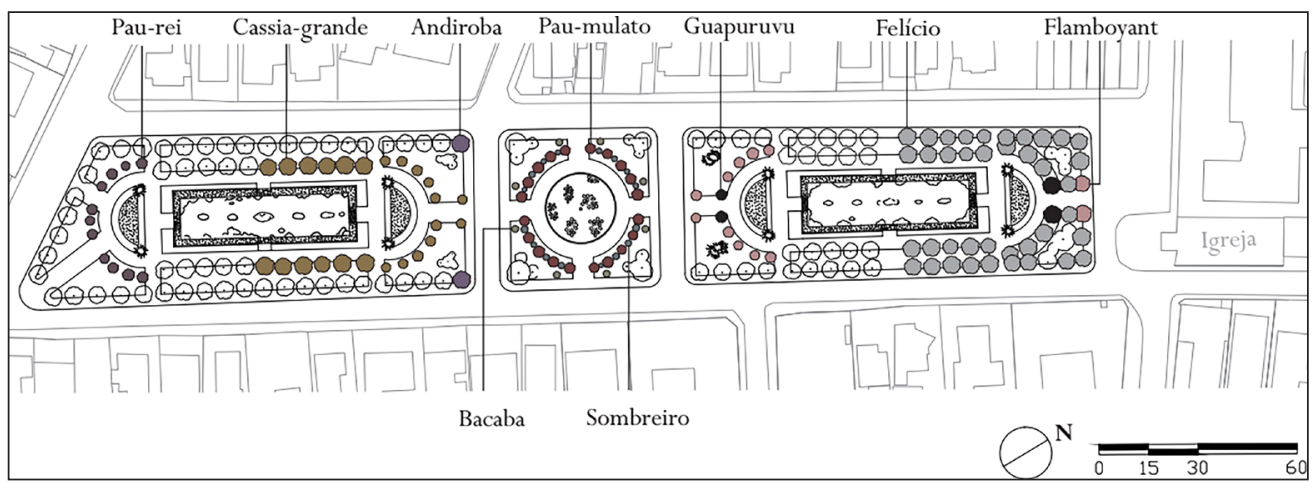

Figura 17 - Praça de Casa Forte. Destaque para as substituições e/ou modificações do local de plantio das espécies Schizolobium amazonicum e Delonix regia no jardim de plantas exóticas. Fonte: Silva (2017, p. 148).

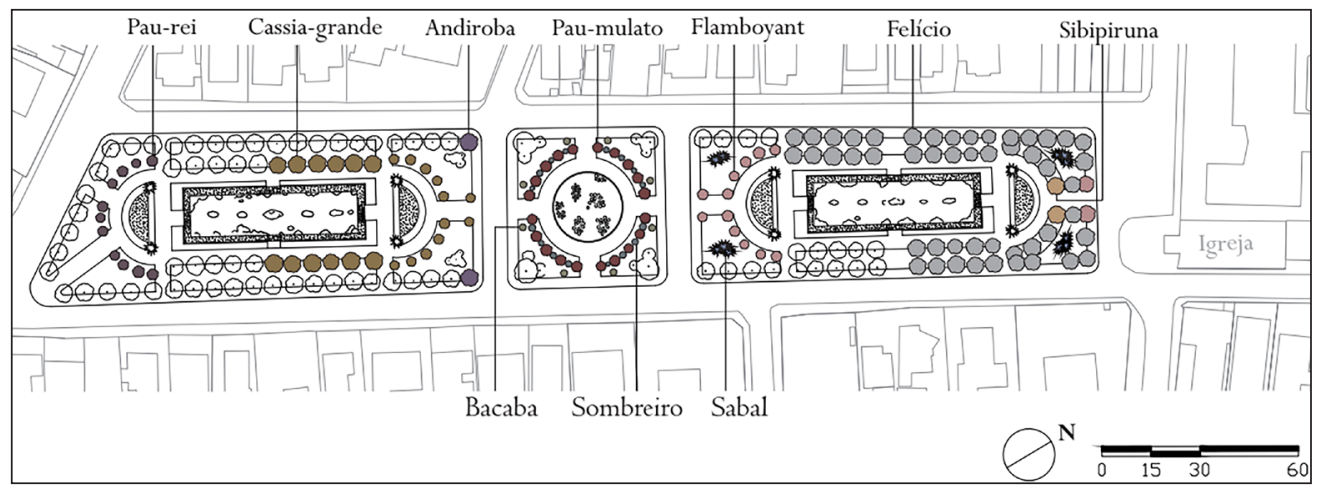

Figura 18 - Projeto da Praça de Casa Forte, composição reconstruída a partir de fontes históricas, fim da década 1940. Fonte: Silva (2017, p. 148).

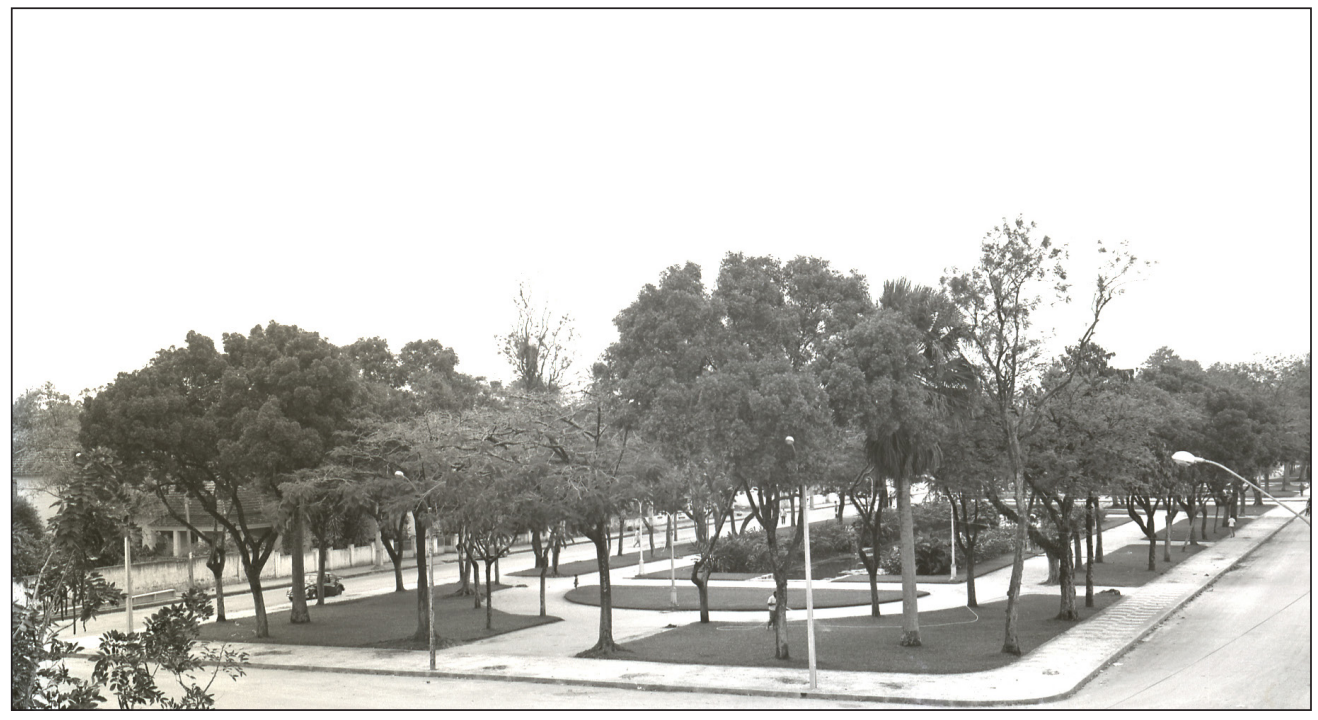

Figura 19 - Praça de Casa Forte. Em primeiro plano e ao centro do canteiro do lado direito e do esquerdo vê-se indivíduos de Sabal palmetto, fim da década de 1940. Fotografia: Alcir Lacerda. Acervo da Família. 
53. Na lenda, a Lua (Jaci, para os índios) era uma deusa que beijava e enchia de luz o rosto da mais bela virgem da aldeia e a levava para si, transformando-a em estrela. Naiá, filha do chefe e princesa da tribo, querendo ser transformada em estrela, perseguia a Lua. Em uma noite, prostrada na margem de um lago mesma posição em que Burle Marx dispõe a índia no espelho d'água -, Naiá vê a lua e imagina que ela teria vindo buscá-la; atirou-se nas águas e nunca mais foi vista. A Lua, em recompensa ao sacrifício da guerreira, transformou-a na "estrela das águas", representada pela vitória-régia (cf. Silva, 2012).

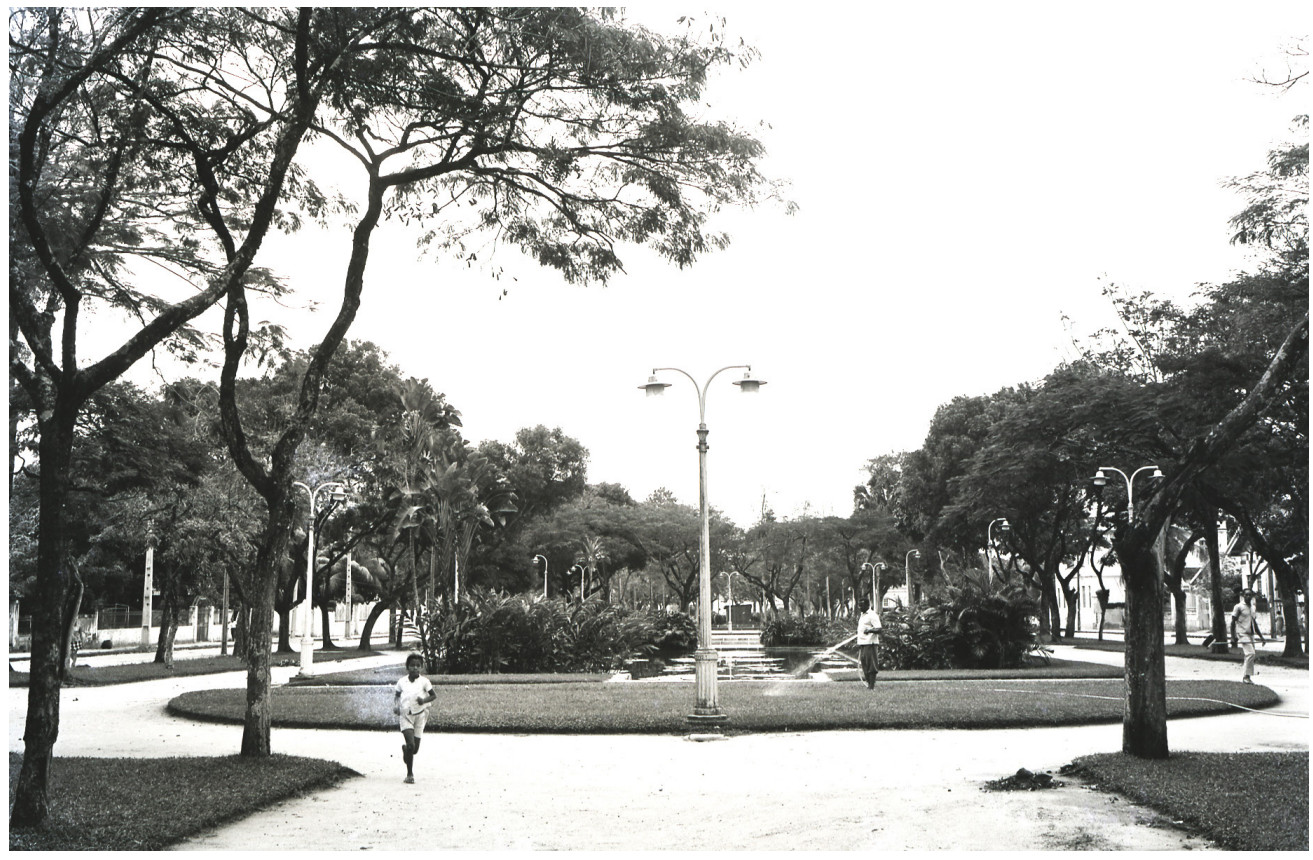

Figura 20 - Praça de Casa Forte. Em primeiro plano veem-se indivíduos de Caesalpinia peltophoroides adultos plantados na área dedicada aos Filicium decipien, fim da década de 1940. Fotografia: Alcir Lacerda. Acervo da família.

Se com a vegetação arbórea as mudanças foram significativas, o que dizer da vegetação herbácea? As primeiras a desaparecerem da praça foram a Victoria amazonica (vitória-régia), o Nelumbo nucifera (lótus), o Juncus effusus (junco), o Cyperus papyrus (papiro), o Evolvulus pusillus (orvalho) e a Canna indica (cana-da-índia), como se constatou nas iconografias do início da década de 1940. É nesse momento que a palmeira Dypsis lutescens (areca) passa a configurar as jardineiras dos lagos da Praça de Casa Forte.

Outro ponto importante na composição da Praça de Casa Forte foi a indicação da escultura de uma índia a se banhar. Além de uma questão artística de perfeita integração com o motivo do jardim, a região amazônica, a escultura traz outros significados. Diante da cientificidade que Burle Marx empregava em seus jardins mediante o manejo da vegetação, o aspecto cultural de cada região - o saber popular - também era forte ao projetar. $\bigcirc$ paisagista desenha a escultura da índia rodeada por Victoria amazonica (vitória-régia). O significado por trás desses elementos - a índia e a Victoria amazonica - possivelmente está relacionado à lenda tupi-guarani sobre a guerreira Naiá. ${ }^{53}$ De acordo com Tabacow, "o contato com as paisagens, com os costumes do interior, com as 
cores de cada região eram fontes permanentes de idéias, de inspiração, de invenção". 54

Os elementos naturais da paisagem do Recife estimularam Burle Marx a pensar o desenho da Praça de Casa Forte e também serviram de pano de fundo para o paisagista. Nas palavras de Janete Costa, ${ }^{55}$ é como se Burle Marx dissesse: "isto aqui eu estou fazendo, a natureza está ali. Mas o que ocorre é a ligação do jardim com a paisagem local".

A grandiosidade e a força do projeto da Praça de Casa Forte são tais, que mesmo com todas as mudanças ocorridas, principalmente a partir da década de 1940, por falta de uma correta manutenção, ela continua sustentando o título de "o mais Bello jardim de Recife", 56 como foi considerada em 1936, quando estava em seu auge.

\section{CONCLUSÃO}

Obra de arte concebida por Burle Marx. Monumento criado a priori por Roberto Burle Marx. Por tais características a Praça de Casa Forte é considerada patrimônio cultural do Brasil. Ao projetar treze jardins na cidade de Recife, entre os anos de 1935 e 1937, Burle Marx implanta no Brasil o "jardim moderno".

A modernidade chega aos jardins tendo como protagonistas a vegetação autóctone e a valorização das espécies naturalizadas que já faziam parte da paisagem recifense. A escultura da índia a se banhar, figura humana típica principalmente da região amazônica, é destaque na composição da Praça de Casa Forte para evocar a brasilidade. A importância que Burle Marx deu ao efeito desse elemento também estava na imobilidade serena que se acentua, contrastando com o dinamismo e as transformações contínuas da vegetação.

A diversidade vegetal que Burle Marx empregou na Praça de Casa Forte e nos outros doze jardins fez Recife ganhar destaque como símbolo de cidade moderna nos principais jornais do Brasil nos anos 1930. De extrema beleza e também por suas peculiaridades, as espécies vegetais dividiram as opiniões.

Ao importar ou coletar espécies com indivíduos já adultos, e muitas vezes com mais de três metros de altura, Burle Marx não esperou o jardim chegar à maturidade para mostrar seu esplendor. Para a Praça de Casa Forte, - Jardim Botânico do Rio de Janeiro teve um papel fundamental ao fornecer algumas espécies raras. Ao colocar como prioridade o "valor de observar, de ver", Burle Marx, com seu olhar de artista sobre nossas florestas - e com o filtro 
da fitoassociação -, selecionou espécies que pela primeira vez foram usadas em um projeto de jardim.

A admiração diante dos jardins projetados por Burle Marx no período em que ele permaneceu em Recife fez intelectuais, a exemplo do engenheiro e poeta Joaquim Cardozo, considerarem o trabalho do paisagista como a realização de uma estrutura das mais amplas e variadas, e tudo isso foi feito em meio a uma luta tenaz para que seu ponto de vista fosse aceito.

Por sua vez, a conservação de um jardim histórico não é algo fácil, principalmente no que se refere ao componente vegetal, por seu ciclo biológico. O ideal será atuar com uma "conservação indireta", cujo objetivo é retardar ou impedir o restauro diretamente sobre o objeto. A conservação indireta compreende um conjunto de operações de conhecimento e análise, bem como uma série de ações que se executam sem intervir de modo direto sobre o jardim.

Deste modo, por toda a dinâmica e exigência que o vegetal impõe, são necessários profissionais específicos da área de jardinagem. Aqui eleva-se a importância dos jardineiros que dominem não só a variável planta, mas também - e principalmente - a história do jardim e as técnicas relacionadas à qualidade do solo e à fitossanidade (esta última por possibilitar o prolongamento da vida do vegetal). A análise fitossanitária deve ser realizada de maneira mais acentuada nos indivíduos antigos - o verde histórico. Outro ponto de extrema importância para a conservação do jardim histórico é a criação de viveiros específicos, porque isso garantirá o fornecimento de mudas e consequentemente ações efetivas de conservação que possibilitarão a permanência dos valores patrimoniais, da autenticidade, da integridade e da significância. 


\section{REFERÊNCIAS}

FONTES IMPRESSAS

BORBA, Lauro. Quem nos dera! Diario de Pernambuco, Recife, p. 2, 8 jun. 1937.

BRAZILIAN FLOWERS. Revista cidade maravilhosa, Rio de Janeiro, p. 44, 1936.

DIARIO DA MANHÃ. Recife, p. 8, 26 jan. 1936.

JARDINS brasileiros com flora brasileira: brejo e caatinga, plantas dos desertos e das aguas com motivos ornamentaes. O carioca, Rio de Janeiro, p. 32, 20 jun. 1936.

JARDINS brasileiros para as cidades do Brasil: o novo tipo de ajardinamento inaugurado no Recife. A noite, Rio de Janeiro, p. 3, 27 mar. 1938.

MARX, Roberto Burle. O jardim da Casa Forte. Diario da manhã, Recife, p. 1-12, 22 maio 1935.

MELO, Mário. Ontem, hoje e amanhã. Jornal Pequeno, Recife, p. 1, 17 maio 1935a.

MELO, Mário. Ontem, hoje e amanhã. Jornal Pequeno, Recife, p. 1, 8 jun. 1935 b.

NOTICIARIO e atividades várias. Rodriguesia, Rio de Janeiro, p. 102, 1935.

OBRA descaracteriza Praça de Casa Forte. Jornal do Commercio, Recife, p. 1, 22 set. 1998.

PERNAMBUCO e Recife sob o signo do Estado novo: os grandes melhoramentos públicos, realizados na capital, na administração Novaes Filho. O cruzeiro, Rio de Janeiro, ano 11, n. 47, p. 3-4, 1939. 
AÑÓN FELIÚ, Carmen. El jardín histórico: notas para una metodología previa al proyecto de recuperación. In: INTERNATIONAL SCIENTIFIC COMMITTEE ON CULTURAL LANDSCAPES. Jardins et sites historiques. Madrid: Doce Calles, 1993. p. 312-325.

ASSUNTO, Rosario. Il paesaggio e l'estetica. Nápoles: Giannini, 1973.

BATTISTI, Eugenio. Reinventando per il futuro i giardini del passato. In: CAZZATO, Vincenzo (org.). Tutela dei giardini storici. Roma: Ministero dei Beni Culturali Ambientali, Bilanci e Prospettive, 1989.

CARDOZO, Joaquim. A Diretoria de Arquitetura e Urbanismo (DAU): olhada de um ponto de vista atual. In: MACEDO, Danilo Matoso; SOBREIRA, Fabiano José Arcadio (eds.). Forma e estética: ensaios de Joaquim Cardozo sobre arquitetura e engenharia. Brasília, DF: Edições Câmara, 2009. p. 171-176.

CONSELHO INTERNACIONAL DE MONUMENTOS E SíTIOS. Comitê Internacional de Jardins e Sítios Históricos. Carta de Florença. Florença. Icomos-IFLA, 21 maio 1981. Disponível em: <https://bit.ly/2Snpveh>. Acesso em: 30 nov. 2018.

CORREIA, Telma de Barros. Art déco e indústria: Brasil, décadas de 1930 e 1940 . Anais do Museu Paulista, São Paulo, v. 16 n. 2, p. 47-104, 2008.

DE ANGELIS, Bruno Luiz Domingos; DE ANGELIS NETO, Generoso. Jardins históricos: introduzindo a questão. Paisagem e Ambiente, São Paulo, n. 19, p. 31-34, 2004.

DOURADO, Guilherme Onofre Mazza. Modernidade verde: jardins de Burle Marx. 2000. Dissertação (Mestrado em Arquitetura e Urbanismo) - Departamento de Arquitetura e Urbanismo, Universidade de São Paulo, São Paulo, 2000.

GIEDION, Siegfried. Le Brésil et l'architecture contemporaine. L'Architecture d'Aujourd'bui, Paris, ano 23, p. 42-43, 1952.

HAJÓS, Géza. Jardines históricos y paisajes culturales: conexiones y límites. Teorías y experiencias en Austria. In: SEMINARIO INTERNACIONAL LOS JARDINES HISTORICOS. 1., 2001, Buenos Aires. Anais [...] Buenos Aires: Icomos, 2001. p. 1-9.

HAMERMAN, Conrad. Burle Marx vive. The Journal of Decorative and Propaganda Arts, Flórida, n. 21, p. 156-179, 1995. 
INTERNATIONAL SCIENTIFIC COMMITTEE ON CULTURAL LANDSCAPE. Recommandations. In: COLLOQUE SUR LA CONSERVATION ET LA RESTAURATION DES JARDINS HISTORIQUES. 1., 1971, Fontainebleau. Anais [...]. Fontainebleau: Icomos-IFLA, 1971. p. 37-42.

LEENHARDT, Jacques. O jardim: jogos de artifícios. In: LEENHARDT, Jacques (ed.). Nos jardins de Burle Marx. São Paulo: Perspectiva, 2006. p. 7-46.

MARX, Roberto Burle. Arte e Paisagem. São Paulo: Nobel, 1987.

MIRANDA, Maria do Carmo Tavares de (org.). Anais do Seminário de Tropicologia: homem, terra e trópico. Recife: Massangana, t. 19, 1992. 276 p.

PECHERE, René. La restauration des jardins historiques et la philosophie du colloque. In: ICOMOS-IFLA. Primer COLLOQUE SUR LA CONSERVATION ET LA RESTAURATION DES JARDINS HISTORIQUES. Fontainebleau: Icomos-IFLA, 1971. p. 17-20.

PELEGRINI, Sandra. Cultura e natureza: os desafios das práticas preservacionistas na esfera do patrimônio cultural e ambiental. Revista Brasileira de História, São Paulo, v. 26, n. 51, p. 115-140, 2006.

RICKLEFS, Roberto Eric. A economia da natureza. Rio de Janeiro: Guanabara Koogan, 2003.

SÁ CARNEIRO, Ana Rita et al. The complexity of historic garden life conservation. In: ZANCHETI, Sílvio; SIMILÄ, Katrina (eds.). Measuring heritage conservation performance. Rome: ICCROM, 2012. p. 33-41.

SIQUEIRA, Vera Beatriz. Permanence et diversité: aspects du modernisme des jardins de Burle Marx. Brésil(s), Paris, v. 12, p. 1-17, 2017 a.

SIQUEIRA, Vera Beatriz. Santo Antonio da Bica: as coleções de Roberto Burle Marx. Modos, Campinas, v. 1, n. 1, p. 90-112, $2017 \mathrm{~b}$.

SILVA, Joelmir Marques da. Arqueologia botânica dos jardins de Burle Marx: a Praça de Casa Forte e a Praça Euclides da Cunha. 2012. Dissertação (Mestrado em Desenvolvimento Urbano) - Departamento de Arquitetura e Urbanismo, Universidade Federal de Pernambuco, Recife, 2012.

SILVA, Joelmir Marques da. Integridade visual nos monumentos vivos: os jardins históricos de Roberto Burle Marx. 2017. Tese (Doutorado em Desenvolvimento Urbano) - 
Departamento de Arquitetura e Urbanismo, Universidade Federal de Pernambuco, Recife, 2017.

TABACOW, José. Universalidade de Roberto Burle Marx. Revista Brasileira de Horticultura Ornamental, Campinas, v. 2, n. 1, p. 1-3, 1996.

TABACOW, José. [Entrevista cedida a] Abilio Guerra. Entrevista. Vitruvius, São Paulo, ano 7, n. 28.02, out. 2006. Disponível em: <https://bit.ly/2QqRbS9>. Acesso em: 30 nov. 2018.

VARINE-BOHAN, Hughes de. A experiência internacional: notas de aula. São Paulo: FAUUSP, 1974.

Artigo apresentado em 29/06/2018. Aprovado em $31 / 10 / 2018$.

\section{(cc) BY}

All the contents of this journal, except where otherwise noted, is licensed under a Creative Commons Attribution License 